\title{
Inefficiencies Caused by Non-harmonized Capacity Mechanisms in an Interconnected Electricity Market
}

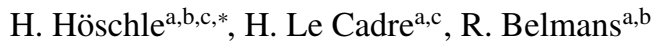 \\ ${ }^{a}$ EnergyVille, Thorpark 8310, 3600 Genk, Belgium \\ ${ }^{b}$ KU Leuven, Electa, Kasteelpark Arenberg 10, 3001 Leuven, Belgium \\ ${ }^{c}$ VITO, Boeretang 200, $2400 \mathrm{Mol}$, Belgium
}

\begin{abstract}
The European Internal Energy Market consists of many interconnected market zones. Unless transmission capacities are constrained, these market zones share capacity assets and injected energy to the benefit of the system. Market and price coupling allows making use of resources more efficiently. These efficiency gains are grounded on the harmonization of system operation and market rules. However, various capacity mechanisms (CMs) are put in place on national level that undermine the process of harmonization and complicate efficient market coupling. This paper addresses the inefficiencies caused by non-harmonized CMs. We propose a novel model formulation including generators, a market operator, an interconnection operator and an aggregated set of consumers. The model combines market clearings with investment decision in generation and transmission. The formulation allows for multiple market zones with different CMs. The model is set up as non-cooperative game whose properties are analyzed through the computation of a Nash Equilibrium. The model quantifies average cost, energy not served, and reserve margins per zone and system. The changing net exchange between markets and installed capacities are evaluated. A case study with three zones highlight the inefficiencies of wrongly estimating the contribution from neighboring market zones. These can be reduced by a shared assessment of capacity demands in coupled CMs and cross-border participation. A sensitivity analysis distinguishes explicit and implicit cross-border contributions. The results suggest that a common approach to CMs yields beneficial outcomes from a regional perspective. However, wrong estimation (under or over) of cross-border participation leads to different economic inefficiencies.
\end{abstract}

Keywords: Capacity Mechanisms, Cross-border Participation, Internal Energy Market, Market Coupling, Market Equilibrium

\section{Introduction}

This paper addresses the current discussion about the implementation and harmonization of capacity mechanisms (CMs) in EU Member States. In order to quantify the inefficiencies that 5 result from non-harmonized CMs, we highlight important market parameters that affect the efficiency of CM harmonization and cross-border participation.

\subsection{Internal Energy Market and capacity mechanisms}

The European Internal Energy Market (IEM) consists of many interconnected market zones. Unless transmission capacities are constrained, these market zones share capacity assets and injected energy to the benefit of the system. The overarching target set by the European Commission for the IEM [1] is to create an adequately interconnected, market-based energy 15 system. Market signals should create incentives for necessary investments into generation and transmission. Such a market would yield the economically most effective outcome and minimize the need for state-planned investments.

\footnotetext{
${ }^{*}$ Corresponding author

Email address: hanspeter.hoschle@energyville. be (H. Höschle)
}

However, there are doubts about the capability of the current market to attract adequate investments to ensure the current level of security of supply. The European Commission [1] acknowledges that shortcomings of the current market arrangements reduce the attractiveness for new investments.

CMs are considered in many EU Member States as a means to address national concerns about generation adequacy. Market frameworks are redesigned accordingly [2]. CMs can take various forms, such as direct capacity payments, market-wide capacity markets, reliability options, or targeted strategic reserves. Their varying working principles, participation rules and impact on the market outcome have been discussed and analyzed. An overview of currently implemented CMs can be found for example in [3]. A recent survey shows that many markets worldwide implement CMs for different reason including lack of interconnection, increased shares of Renewable Energy Sources (RES), or seasonal demand fluctuations [4].

However, in the context of the European IEM, non-harmonized CMs in the interconnected energy system is an additional threat for the efficiency of the market operation. According to [5], different degrees of harmonization are possible. However, national market redesigns seem to aim at national generation adequacy rather than seeking a wider regional coordination. The resulting patchwork of different CMs undermines the 
harmonization process. The European Commission [1] clearly states that if implemented, CMs should be designed to minimize distortions to the IEM.

In a setting with $\mathrm{CMs}$, the participation in the $\mathrm{CM}$ of capacity suppliers from neighboring markets, i.e., cross-border participation, is promoted to increase efficiency. Following the European Commission [6], cross-border participation ensures duces the long-term costs of security of supply. However, the efficiency depends on how remunerations are affected and the decision-making of market participants changed accordingly. Variations in remuneration of assets in the individual markets could lead to welfare losses [7].

\subsection{Cross-border participation in capacity mechanisms}

Assuming that the decision for or against a CM was taken based on clearly identified needs, cross-border participation is a means to make best use of assets in neighboring markets that 60 contribute to generation adequacy. For that reason, the European Commission [8] argues that generation adequacy assessments need to take into account interconnection capacity and non-domestic generation capacity.

In the literature and in current implementations different 65 forms of cross-border participation can be identified:

- No participation: Non-domestic capacity cannot participate because flows during scarcity are assumed unreliable, e.g., in Spanish, Portuguese capacity payments [6];

- Implicit participation: Non-domestic capacity is deducted from the capacity demand or implicitly accounted for as zero bids, e.g., Italian reliability options [6], Belgian strategic reserves (SR) [9];

- Explicit participation: Non-domestic capacity or interconnectors directly participate and compete with domestic supply. Participation is limited by the de-rating of generation and / or interconnection capacity, e.g., interconnector participation in Great Britain (GB) capacity market [10].

While implicit participation is considered easier to implement because of its estimation during capacity demand assessments, explicit participation and the associated de-rating of capacity might be challenging [11]. The de-rating of capacity is linked to the question of ensuring delivery during scarcity events and the possibility to participate in multiple CMs in neighboring markets. In order to limit the necessary assessments to

85 few interconnection capacities, the interconnector model is preferred by multiple studies. The delivery is easier to follow and the approach offers a direct investment signal for interconnection capacity $[12,13]$. These capacity-based price signals for interconnection improves their economic efficiency [7].

Alternatively, a generator model, i.e., participation of nondomestic capacity, would require an additional auctioning of transmission capacity in either an implicit or an explicit form comparable to practice for energy markets. This could indirectly also provide an investment signal for interconnection capacity.

Several recent studies $[14,15,16]$ show that the harmonization of the CMs itself, combined with cross-border participation across multiple markets, is beneficial. Non-harmonized implementations of CMs could reduce economic efficiency and even negatively affect the security of supply. Moreover, the implementation of a CM in one market may cause pressure on neighboring countries to implement a CM as well [15]. In addition to harmonization, [16] highlight that a regional capacity assessment and sound de-rating is crucial for the efficiency.

As a goal for harmonization, one could target a fully harmonized and coupled market-based CM with cross-border participation of de-rated generation, load, or storage. The crossborder participation would be determined based on capacity price differentials similar to the energy market. The resulting congestion rents provide a market-based signal for interconnection investment, similar to the interconnector model.

\subsection{Models for interconnected capacity mechanisms}

Different approaches for the assessment of the effects of non-harmonized CMs and cross-border participation can be found in the literature. For example, large-scale system cost minimization models are used [11, 16]. These models focus on potential cross-border participation via probabilities of contribution to security of supply but they do not differentiate among different CMs. [15] proposes an agent-based model with expertrules to judge investment based on net present value (NPV) in a setting with interconnected SR and capacity markets. However, no cross-border participation is included. [14, 17] apply stylized analytical equilibrium models. These models are limited in the representation of operational details and RES participation. Based on a load duration curve, their models quantify price, capacity and welfare effects.

An equilibrium model with hourly operational details and representation of different CMs is proposed in [18]. Market participants are modeled as individual agents that take investment and operational decisions under the assumption of perfect competition. The model is extended in [19] to two symmetrical interconnected market zones. Its focus is to analyze the impact of increasing interconnection capacity on generation adequacy with different combinations of CMs. However, the model does not account for cross-border participation and only provides results in a symmetrical case. In this paper, we formulate an extension to that model which allows for more far-reaching studies.

\subsection{Contributions}

The contribution of the paper is threefold. First, we propose a novel model formulation to represent a market setting of interconnected market zones that may implement different CMs. In particular, this can be in form of SR or a capacity market. Hereby, the model is not limited in the number of market zones or configuration of the CMs. In comparison to similar model approaches, the proposed model combines hourly temporal resolutions for operational details with investment in generation and transmission. Additionally, the modeling approach incorporates the possibility to study cross-border participation in CMs, which is assumed either to be implicit or explicit. 
Second, we apply game theory to the proposed model formulation and set up a non-cooperative game. Each market participant acts independently and simultaneously. It selfishly maximizes its own utility, e.g. profits or surplus. We apply the solution concept of Nash Equilibrium (NE) and use the obtained equilibrium for the economic interpretation of different market settings. We apply the proposed model in a case study with three markets including different scenarios. The scenarios differ in the choice of CMs and the incorporation of cross-border tribution.

Finally, the obtained equilibria are compared based on indicators derived from the installed capacities, market prices and market volumes. We use the results for an economic analysis. The results are used to quantify efficiency losses caused by non-harmonized CMs. Generalizable findings are put forward by clearly pointing out the benefits of harmonizing CMs and studying the efficiency gains through cross-border participation. An additional focus is put on the de-rating of interconnections and its implication on the system cost and reliability.

The paper is organized as follows. Section 2 describes the mathematical formulation of the game including the optimization problem of all market participants. Section 3 outlines the case study and the assumed scenarios. The results of the case study are summarized and discussed in Section 4. The paper ends with conclusions presented in Section 5.

\section{Multi-market model with capacity mechanisms}

In this section, the proposed market model is introduced. The assumption about the modeled CMs are outlined. The game-theoretic model with the agents is described. The agents include generators, a market and an interconnection operator, and non-atomic consumers aggregated as a single agent. Table 1 lists all used symbols.

\subsection{Markets for energy, RES certificates, and capacity}

We build upon the model descriptions of markets for energy, RES certificates, and capacity provided in [18, 19]. Four different markets are implemented in the model (Fig. 1).

First, an hourly market for energy represents the predominant energy markets implemented in many market zones (Fig. 1a). The hourly demand for energy is assumed to be moderately price-elastic resulting in a sloped demand curve up to the price cap, $\overline{\lambda_{z}^{\mathrm{e}}}$, set for each market zone $z \in \mathcal{Z}$. The slope is defined by a reference price, $\lambda_{z}^{\mathrm{e} \#}$, and an inverse price-elasticity, $M_{z}^{\mathrm{e}}$. An extended discussion on modeling price-elastic demand is provided in [20].

Second, a market for RES certificates is introduced (Fig. 1b). This market represents a minimum demand for energy originating from RES in each market zone $z \in \mathcal{Z}$. The demand is assumed to be inelastic and the remuneration for RES can reach up to a maximum price, $\overline{\lambda_{z}^{\mathrm{r}}}$. The resulting price, $\lambda_{z}^{\mathrm{r}}$, forms an additional revenue stream for RES.

Third, we model the contracting of SR (Fig. 1c) in the market zones $z^{\text {sr }} \in \mathcal{Z}^{\text {sr }} \subseteq \mathcal{Z}$. The model follows current market implementations as for example the Belgian SR [9]. Capacity

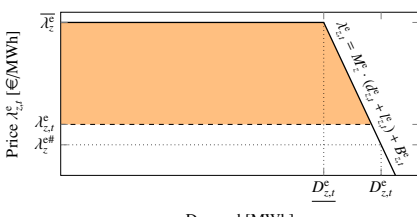

(a) Hourly Energy Market

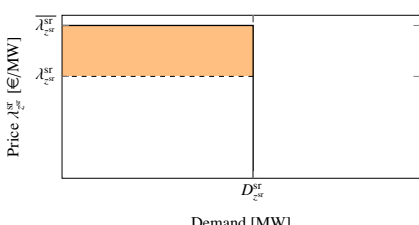

(c) Strategic Reserves

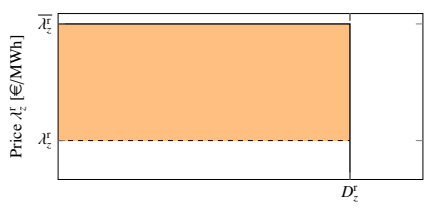

(b) RES certificates

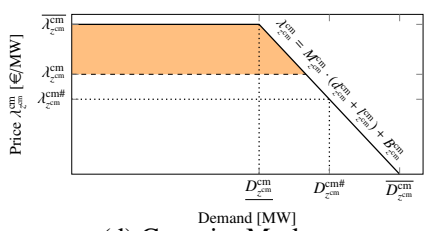

(d) Capacity Market
Figure 1: Schematic demand curves for the four different markets. The graphs show for each market a market clearing, the resulting consumer surplus (colored area), and the associated clearing price $\left(\lambda_{z, t}^{\mathrm{e}}, \lambda_{z}^{\mathrm{r}}, \lambda_{z^{\mathrm{sr}}}^{\mathrm{sr}}, \lambda_{z^{\mathrm{cm}}}^{\mathrm{cm}}\right)$.

contracted in the SR is taken out of the energy market. The demand of the SR, $D_{z^{\mathrm{st}}}^{\mathrm{sr}}$, is assumed to be inelastic. The contracted capacity is remunerated with the resulting capacity price $\lambda_{z^{\mathrm{r}}}^{\mathrm{sr}}$. This capacity price is limited by a price cap, $\overline{\lambda_{z^{\mathrm{s}}}^{\mathrm{sr}}}$, equal to the Cost Of New Entry (CONE). The contracted capacity in market zone $z^{\text {sr }}$ is only activated by the system operator to prevent Energy Not Served (ENS), hence, only if the energy market cannot clear demand and supply in market zone $z^{\text {sr }}$. Therefore, the activation price of SR is equal to the price cap on the energy-based market, $\overline{\lambda_{\text {sr }}^{\mathrm{e}}}$.

Fourth, a market-wide capacity market (Fig. 1d) is modeled following current implementations in place, e.g., in GB [10]. For each market zone $z^{\mathrm{cm}} \in \mathcal{Z}^{\mathrm{cm}} \subseteq \mathcal{Z}$, a sloped capacity demand curve is defined around three price-quantity points de-

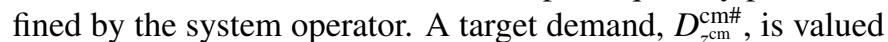
with a target price, $\lambda_{z^{\mathrm{cm}}}^{\mathrm{cm}}$, typically set to the Net Cost Of New Entry (Net CONE). A minimum demand for capacity, $D_{z^{\mathrm{cm}}}^{\mathrm{cm}}$ is valued with the maximum price, $\overline{\lambda_{z^{\mathrm{cm}}}^{\mathrm{cm}}}$. The maximum demand, $\overline{D_{z^{\mathrm{cm}}}^{\mathrm{cm}}}$, defines the maximum volume for which a capacity price is paid.

We assume that an hourly energy market and a market for RES certificates are part of each market zone. The implementation of a CM is case-dependent.

\subsection{Capacity expansion planning in multiple market zones}

We propose a non-cooperative game with market clearing conditions. The schematic set-up of the model is presented in Fig. 2. Different agents compete and take decisions about market volumes and market prices independently and simultaneously. The set of agents is defined as $\mathcal{A}:=\left(G_{i}\right)_{i \in \mathcal{N}} \cup\{c\} \cup \mathrm{IO} \cup$ MO. It contains price-taking generators $\left(G_{i}\right)_{i \in \mathcal{N}}$, a price-taking consumer $c$, a price-taking operator of the interconnector IO, and a price-setting market operator MO.

Formally, each agent $a \in \mathcal{A}$ decides on its strategy $\chi_{a}$ that is in its set of strategies $\mathcal{X}_{a}$. We denote $\mathcal{X}:=\times_{a \in \mathcal{A}} \mathcal{X}_{a}$ as the set of all possible combinations of strategies. The utility function of each agent $a \in \mathcal{A}$ is defined as $\Pi_{a}: \mathcal{X} \rightarrow \mathbb{R}$. This setting gives rise to a non-cooperative game $\Gamma:=\left(\mathcal{A}, \mathcal{X},\left(\Pi_{a}\right)_{a \in \mathcal{A}}\right)$, which is 
Table 1: Nomenclature

\begin{tabular}{|c|c|c|c|c|c|}
\hline Sets & & & $D_{z^{\mathrm{cm}}}^{\mathrm{cm} \#}$ & Target capacity demand in zone $z^{\mathrm{cm}}$ & $M W$ \\
\hline $\mathcal{T}$ & Set of time steps $t$ & & $D_{z^{\mathrm{cm}}}^{\mathrm{cm}}, \overline{D_{z^{\mathrm{cm}}}^{\mathrm{cm}}}$ & Capacity demand limits in zone $z^{\mathrm{cm}}$ & $M W$ \\
\hline $\mathcal{Z}$ & Set of market zones $z$ & & $\overline{\lambda_{-\mathrm{cm}}^{\mathrm{cm} \#}}$ & Target price cap for capacity in zone $z^{\mathrm{cm}}$ & $€ / M W$ \\
\hline $\mathcal{Z}^{\text {sr }} \subseteq \mathcal{Z}$ & Set of market zones with strategic reserves & & $\frac{z^{\mathrm{min}}}{\lambda_{z^{\mathrm{cm}}}^{\mathrm{cm}}}$ & Price cap for strategic reserve in zone $z^{\mathrm{cm}}$ & $€ / M W$ \\
\hline $\begin{array}{l}\mathcal{Z}^{\mathrm{cm}} \subseteq \mathcal{Z} \\
\mathcal{A}\end{array}$ & $\begin{array}{l}\text { Set of market zones with capacity market } \\
\text { Set of agents }\end{array}$ & & \multicolumn{3}{|c|}{ Strategies of agents (decision variables) } \\
\hline N & Set of generators $i$ & & $\chi_{i}$ & Strategy of generator $i$ & \\
\hline $\mathcal{X}_{i}$ & Set of strategies for generator $i$ & & $g_{i, z, t}$ & Energy output of generator $i$ in zone $z$ & $M W h$ \\
\hline$X_{c}$ & Set of strategies for consumer $c$ & & $\operatorname{cap}_{i, z}$ & Installed capacity of generator $i$ in zone $z$ & $M W$ \\
\hline$X_{\mathrm{IO}}$ & Set of strategies for interconnection operato & & $r_{i, z}$ & RES injection of generator $i$ in zone $z$ & $M W h$ \\
\hline$X_{\mathrm{MO}}$ & Set of strategies for market operator MO & & $\operatorname{cap}_{i, z, z^{\mathrm{sr}}}^{\mathrm{sr}}$ & Capacity of $i$ in zone $z$ offered in zone $z^{\mathrm{sr}}$ & $M W$ \\
\hline$x$ & Set of all combinations of strategies & & $\operatorname{cap}_{i, z, z^{\mathrm{cm}}}^{\mathrm{cm}}$ & Capacity of $i$ in zone $z$ offered in zone $z^{\mathrm{cm}}$ & $M W$ \\
\hline Parameters & & & $\chi_{c}$ & Strategy of consumer $c$ & \\
\hline$W_{t}$ & Weighting factor of each time step & & $d_{z, t}^{\mathrm{e}}$ & Energy demand in $z$ & $M W h$ \\
\hline$F_{z, z^{\mathrm{sr}}}^{\mathrm{sr}}, F_{z, z^{\mathrm{cm}}}^{\mathrm{cm}}$ & De-rating factor for interconnection & & $\begin{array}{l}l_{z, t}^{\mathrm{e}} \\
l_{z}^{\mathrm{r}}\end{array}$ & $\begin{array}{l}\text { Energy Not Served in } z \\
\text { RES certificates not served in } z\end{array}$ & $\begin{array}{l}M W h \\
M W h\end{array}$ \\
\hline$C_{i, z}^{\mathrm{G}}$ & Variable cost of generation & $€ / M W h$ & $g_{z^{\mathrm{sr}}, t}^{\mathrm{sr}}$ & Generation from SR during activation & $M W h$ \\
\hline$C_{i, z}^{\mathrm{I}}$ & Annualized fixed cost & $€ / M W$ & $l_{z \mathrm{sr}}^{\mathrm{sr}}$ & Capacity not contracted for SR & $M W$ \\
\hline$R_{i, z}$ & ramping capability & $\% / h$ & $d_{z^{\mathrm{cm}}}^{\mathrm{cm}}$ & Capacity demand for capacity market & $M W$ \\
\hline$A_{i, z, t}$ & Underlying profile of availability & - & $l_{z^{\mathrm{cm}}}^{\mathrm{cm}}$ & Capacity not contracted for CCM & $M W$ \\
\hline & De-rating factor for RES energy & - & $\chi_{\mathrm{IO}}$ & Strategy of consumer IO & \\
\hline$F_{i, z, z^{\mathrm{sr}}}^{\mathrm{sr}}, F_{i, z, z^{\mathrm{cm}}}^{\mathrm{cm}}$ & De-rating factor for capacity mechanisms & - & $f_{z, z^{\prime}, t}^{\mathrm{e}}$ & Energy flows from zone $z$ to zone $z^{\prime}$ & $M W h$ \\
\hline $\begin{array}{l}D_{z, t}^{\mathrm{e}} \\
\lambda^{\mathrm{e} \#}\end{array}$ & $\begin{array}{l}\text { Reference energy demand in zone } z \text { in } t \\
\text { Reference price for energy in zone } z\end{array}$ & $\begin{array}{r}M W h \\
€ / M W h\end{array}$ & icap & Interconnection from zone $z$ to zone $z^{\prime}$ & $M W$ \\
\hline$\frac{\lambda_{z}}{\lambda_{z}^{\mathrm{e}}}$ & Price cap for energy in zone $z$ & $€ / M W h$ & $\lambda_{\mathrm{MO}}$ & Strategy of consumer $\mathrm{MO}$ & \\
\hline$M_{z}^{\mathrm{e}}$ & Inverse price-elasticity in market zone $z$ & $€ / M W h^{2}$ & $\lambda_{z, t}^{\mathrm{e}}$ & Hourly price for energy output in zone $z$ & $€ / M W h$ \\
\hline$\underline{D_{z}^{\mathrm{r}}}$ & RES target in zone $z$ & $M W h$ & $\lambda_{z}^{r}$ & Price for RES injection in zone $z$ & $€ / M W h$ \\
\hline$\overline{\lambda_{z}^{\mathrm{r}}}$ & Price cap for RES target in zone $z$ & $€ / M W h$ & $\lambda_{z^{\mathrm{ss}}}^{\mathrm{sr}}, \lambda_{z^{\mathrm{cm}}}^{\mathrm{cm}}$ & Price for capacity in zone $z^{\mathrm{sr}}, z^{\mathrm{cm}}$ & $€ / M W$ \\
\hline$\underline{D_{z^{\mathrm{rr}}}^{\mathrm{sr}}}$ & Volume of strategic reserve in zone $z^{\text {sr }}$ & $M W$ & $\lambda_{z, z^{\mathrm{sr}}}^{\mathrm{sr}}, \lambda_{z, z^{\mathrm{cm}}}^{\mathrm{cm}}$ & $\begin{array}{l}\text { Price for transmission rights from zone } z \text { to } \\
-\mathrm{sr}-\mathrm{cm}\end{array}$ & $€ / M W$ \\
\hline$\overline{\lambda_{z^{\mathrm{sr}}}^{\mathrm{sr}}}$ & Price cap for strategic reserve in zone $z^{\text {sr }}$ & $€ / M W$ & & & \\
\hline
\end{tabular}

formulated in strategic form. Each agent maximizes selfishly its utility function $\Pi_{a}$.

The strategies of all agents in $\mathcal{A}$ other than $a$ are defined as $\chi_{\text {-a }}$. Formally, given the strategies of all the other agents in $\mathcal{A}, \chi_{-a}$, each agent $a \in \mathcal{A}$ solves independently and simultaneously:

$$
\max _{\chi_{a} \in \mathcal{X}_{a}} \Pi_{a}\left(\chi_{a}, \chi_{-a}\right) .
$$

The associated solution concept is that of a NE [21, 22]: 245 a strategy profile $\chi^{\star} \in \mathcal{X}$ is a NE if, and only if, $\Pi_{a}\left(\chi^{\star}\right) \geq$ $\Pi_{a}\left(\chi_{a}, \chi_{-a}^{\star}\right), \forall \chi_{a} \in \mathcal{X}_{a}, \forall a \in \mathcal{A}$. Assuming that the strategy spaces of the agents are convex and bounded, it is possible to prove the existence of a NE. Each agent's utility function, the set of strategies, and the optimization problem faced by each agent are described in detail in the following sections.

In the proposed non-cooperative game, we do not model any hierarchy or collusion of market participants in order to put the focus on the difference in the chosen market setting of each zone. An alternative approach could model, e.g., a market operator anticipating on the generators', consumer's and interconnection operator's reaction in order to set capacity demand or SR volumes. Such a formulation would yield a leader (market operator), multi-follower (generators, consumer, interconnec- tion operator) Stackelberg game, that can be formulated as a bilevel optimization problem [23, 24]. Alternatively, a model that extends on existing bilevel formulation for transmission planning, e.g., [25, 26, 27, 28], could be extended to the proposed framework with different $\mathrm{CMs}$ in multiple market zones.

\subsection{Market operator $M O$}

One market operator, MO, or price-setting agent sets the prices for the different markets, $\lambda_{\mathrm{MO}}=\left(\lambda_{z, t}^{\mathrm{e}}, \lambda_{z}^{\mathrm{r}}, \lambda_{z^{\mathrm{sr}}}^{\mathrm{sr}}, \lambda_{z^{\mathrm{cm}}}^{\mathrm{cm}}, \lambda_{z, z^{\mathrm{sr}}}^{\mathrm{sr}}\right.$, $\left.\lambda_{z, \mathrm{z}^{\mathrm{cm}}}^{\mathrm{cm}}\right) \in \mathcal{X}_{\mathrm{MO}}$, given the market volumes of the other agents $\left(\chi_{i}, \chi_{\mathrm{IO}}, \chi_{c}\right)$. Its utility function is the excess demand on the markets, which is minimized. In other words, it sets the prices such that the market clearing conditions are balanced $(2 \mathrm{a})^{1}$. We can distinguish the prices for the different markets and zones. The energy-market with energy imports and exports results in an hourly price, $\lambda_{z, t}^{\mathrm{e}}$. An annual price, $\lambda_{z}^{\mathrm{r}}$ is set for RES certificates. Similarly, the CMs result in an annual price, $\lambda_{z^{\mathrm{sr}}}^{\mathrm{sr}}, \lambda_{z^{\mathrm{cm}}}^{\mathrm{cm}}$.

${ }^{1}$ For readability, the prices for all market clearings are set by a single agent operating all markets. However, the presented problem is separable into one agent per market, as the utility function and constraints of the markets are not interlinked. 
limited by

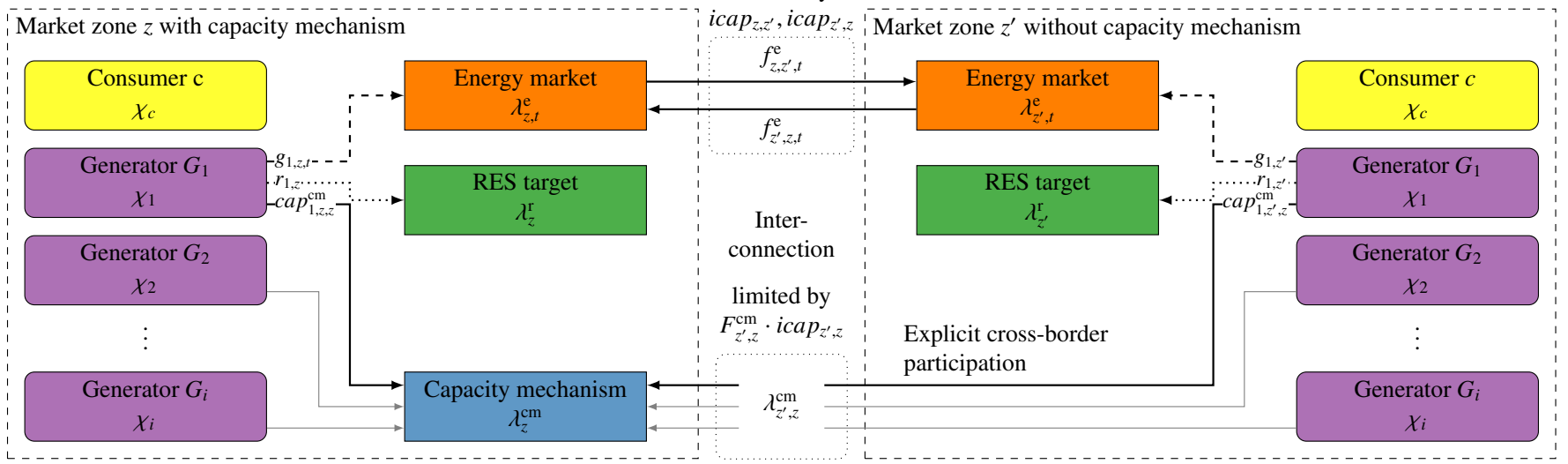

Figure 2: The figure shows schematically the volumes that are are exchanged among the agents. The depicted set-up shows two interconnected market zones of which market zone $z$ operates a capacity mechanism. The generators in zone $z^{\prime}$ may explicitly participate in the capacity mechanism. Their participation is limited by their de-rated capacity $F_{i, z^{\prime}, z}^{\mathrm{cm}} \cdot \operatorname{cap}_{i, z^{\prime}}$ and the de-rated interconnection capacity $F_{z^{\prime}, z}^{\mathrm{cm}} \cdot i c a p_{z^{\prime}, z}$.

Additionally, the explicit auctioning of the transmission capacity for cross-border participation in CMs in neighboring market zones clear at a transmission price, $\lambda_{z z^{\mathrm{sr}}}^{\mathrm{sr}}, \lambda_{z z^{\mathrm{cm}}}^{\mathrm{cm}}$. All prices are limited by an associated price cap, $(2 \mathrm{~b})-(2 \mathrm{~g})$. This yields the following mathematical formulation:

$$
\begin{aligned}
& \min _{\lambda_{\mathrm{MO}} \in \mathcal{X}_{\mathrm{MO}}} \Pi_{\mathrm{MO}}\left(\lambda_{\mathrm{MO}}, \chi_{i}, \chi_{\mathrm{IO}}, \chi_{c}\right)= \\
& \sum_{z \in \mathcal{Z} \backslash \mathcal{Z}^{\mathrm{sr}}}\left[\lambda_{z, t}^{\mathrm{e}} \cdot\left(\sum_{i \in \mathcal{N}} g_{i, z, t}+\sum_{z^{\prime} \in \mathcal{Z}}\left(f_{z^{\prime}, z, t}^{\mathrm{e}}-f_{z, z^{\prime}, t}^{\mathrm{e}}\right)-d_{z, t}^{\mathrm{e}}\right)\right. \\
& +\sum_{z \in \mathcal{Z}^{\mathrm{sr}}}\left[\lambda_{z, t}^{\mathrm{e}} \cdot\left(\sum_{i \in \mathcal{N}} g_{i, z, t}+g_{z, t}^{\mathrm{sr}}+\sum_{z^{\prime} \in \mathcal{Z}}\left(f_{z^{\prime}, z, t}^{\mathrm{e}}-f_{z, z^{\prime}, t}^{\mathrm{e}}\right)-d_{z, t}^{\mathrm{e}}\right)\right. \\
& +\sum_{z \in \mathcal{Z}}\left[\lambda_{z}^{\mathrm{r}} \cdot\left(\sum_{i \in \mathcal{N}} r_{i, z}-D_{z}^{\mathrm{r}}\right)\right] \\
& +\sum_{z^{\mathrm{cm} \in Z^{\mathrm{cm}}}}\left[\lambda_{z^{\mathrm{cm}}}^{\mathrm{cm}} \cdot\left(\sum_{z^{\prime} \in \mathcal{Z}} \sum_{i \in \mathcal{N}} \operatorname{cap}_{i, z^{\prime}, z^{\mathrm{cm}}}^{\mathrm{cm}}-d_{z^{\mathrm{cm}}}^{\mathrm{cm}}\right)\right. \\
& +\sum_{z^{\prime} \in \mathcal{Z}}\left(\lambda_{z^{\prime}, z^{\mathrm{cm}}}^{\mathrm{cm}} \cdot\left(\sum_{i \in \mathcal{N}} \operatorname{cap}_{i, z^{\prime}, z^{\mathrm{cm}}}^{\mathrm{cm}}-F_{z^{\prime}, z^{\mathrm{cm}}}^{\mathrm{cm}} \cdot i c a p_{z^{\prime}, z^{\mathrm{cm}}}\right)\right] \\
& +\sum_{z^{\mathrm{sr}} \in \mathcal{Z}^{\mathrm{sr}}}\left[\lambda_{z^{\mathrm{sr}}}^{\mathrm{sr}} \cdot\left(\sum_{z^{\prime} \in \mathcal{Z}} \sum_{i \in \mathcal{N}} c a p_{i, z^{\prime}, z^{\mathrm{sr}}}^{\mathrm{sr}}+l_{z^{\mathrm{sr}}}^{\mathrm{sr}}-D_{z^{\mathrm{sr}}}^{\mathrm{sr}}\right)\right. \\
& \left.+\sum_{z^{\prime} \in \mathcal{Z}}\left(\lambda_{z^{\prime}, z^{\mathrm{sr}}}^{\mathrm{sr}} \cdot\left(\sum_{i \in \mathcal{N}} c a p_{i, z^{\prime}, z^{\mathrm{sr}}}^{\mathrm{sr}}-F_{z^{\prime}, z^{\mathrm{sr}}}^{\mathrm{sr}} \cdot i c a p_{z^{\prime}, z^{\mathrm{sr}}}\right)\right)\right] \text {, } \\
& \text { s.t. } \quad \lambda_{z, t}^{\mathrm{e}} \leq \overline{\lambda_{z}^{\mathrm{e}}}, \quad \forall z \in \mathcal{Z}, t \in \mathcal{T} \text {, } \\
& 0 \leq \lambda_{z}^{\mathrm{r}} \leq \overline{\lambda_{z}^{\mathrm{r}}}, \quad \forall z \in \mathcal{Z}, \\
& 0 \leq \lambda_{z^{\mathrm{cm}}}^{\mathrm{cm}} \leq \overline{\lambda_{z^{\mathrm{cm}}}^{\mathrm{cm}}}, \quad \forall z^{\mathrm{cm}} \in \mathcal{Z}^{\mathrm{cm}}, \\
& 0 \leq \lambda_{z, z^{\mathrm{cm}}}^{\mathrm{cm}} \leq \overline{\lambda_{z, z^{\mathrm{cm}}}^{\mathrm{cm}}}, \quad \forall z \in \mathcal{Z}, z^{\mathrm{cm}} \in \mathcal{Z}^{\mathrm{cm}}, \\
& 0 \leq \lambda_{z^{\mathrm{sr}}}^{\mathrm{sr}} \leq \overline{\lambda_{z^{\mathrm{sr}}}^{\mathrm{sr}}}, \quad \forall z^{\mathrm{sr}} \in \mathcal{Z}^{\mathrm{sr}}, \\
& 0 \leq \lambda_{z, z^{\mathrm{sr}}}^{\mathrm{sr}} \leq \overline{\lambda_{z, z^{\mathrm{sr}}}^{\mathrm{sr}}}, \quad \forall z \in \mathcal{Z}, z^{\mathrm{sr}} \in \mathcal{Z}^{\mathrm{sr}} .
\end{aligned}
$$

\subsection{Interconnection operator $I O$}

The interconnection operator, IO, decides on the transmission capacity and facilitates the energy flows over the interconnector between two zones, $\chi_{\mathrm{IO}}=\left(\right.$ icap $\left._{z, z}, f_{z, z, t}^{\mathrm{e}}\right) \in \mathcal{X}_{\mathrm{IO}}{ }^{2}$. The

${ }^{2}$ For readability, the interconnections are described by a single agent operating all interconnections. However, the presented problem is separable into one agent per interconnection, $z \rightarrow z^{\prime}$, which would result in the same equilibrium. operator decides on the energy flows, $f_{z, z^{\prime}, t}^{\mathrm{e}}$, from $z$ to $z^{\prime}$. The utility function of the operator represents the sum of revenues minus the cost of investment (3a). The revenues include the energy price arbitrage and transmission rights for participation in neighboring $\mathrm{CMs}^{3}$. The energy price arbitrage is the price difference multiplied with the transferred energy. The energy flows are limited by the interconnection capacity, icap ${\text { z }, z^{\prime}}(3 \mathrm{~b})$. This yields the following mathematical formulation:

$$
\begin{aligned}
\max _{\chi_{\mathrm{IO}} \in X_{\mathrm{IO}}} \Pi_{\mathrm{IO}}\left(\chi_{\mathrm{IO}}, \lambda_{\mathrm{MO}}\right)=\sum_{z \in \mathcal{Z}} \sum_{z^{\prime} \in \mathcal{Z}} \sum_{t \in \mathcal{T}} W_{t} \cdot\left(\lambda_{z^{\prime}, t}^{\mathrm{e}}-\lambda_{z, t}^{\mathrm{e}}\right) \cdot f_{z, z^{\prime}, t}^{\mathrm{e}} \\
\quad-\sum_{z \in \mathcal{Z}} \sum_{z^{\prime} \in \mathcal{Z}} C_{z, z^{\prime}}^{\mathrm{I}, \mathrm{IO}} \cdot \operatorname{icap}_{z, z^{\prime}} \\
\quad+\sum_{z \in \mathcal{Z}} \sum_{z^{\mathrm{sr}} \in \mathcal{Z}^{\mathrm{sr}}} \lambda_{z, z^{\mathrm{sr}}}^{\mathrm{sr}} \cdot F_{z, z^{\mathrm{sr}}}^{\mathrm{sr}} \cdot i c a p_{z, z^{\mathrm{sr}}} \\
\quad+\sum_{z \in \mathcal{Z}} \sum_{z^{\mathrm{cm} \in \mathcal{Z}^{\mathrm{cm}}}} \lambda_{z, z^{\mathrm{cm}}}^{\mathrm{cm}} \cdot F_{z, z^{\mathrm{cm}}}^{\mathrm{cm}} \cdot i c a p_{z, z^{\mathrm{cm}},} \\
\text { s.t. } 0 \leq f_{z, z^{\prime}, t}^{\mathrm{e}} \leq i c a p_{z, z^{\prime}},\left(\mu_{z, z^{\prime}, t}^{\mathrm{e}}\right), \quad \forall z \in \mathcal{Z}, z^{\prime} \in \mathcal{Z}, t \in \mathcal{T}, \\
\quad \\
\quad i c a p_{z, z^{\prime}} \geq 0, \forall z \in \mathcal{Z}, z^{\prime} \in \mathcal{Z} .
\end{aligned}
$$

\subsection{Generator $\left(G_{i}\right)_{i \in \mathcal{N}}$}

Each generator, $G_{i}$, takes the decision on the offered market volumes and the installed capacity, $\chi_{i}=\left(g_{i, z, t}, r_{i, z}, \operatorname{cap}_{i, z, z^{\mathrm{sr}}}^{\mathrm{sr}}\right.$, $\left.c a p_{i, z, z^{\mathrm{cm}}}^{\mathrm{cm}}, \operatorname{cap}_{i, z}\right) \in \mathcal{X}_{i}$. The decision is described by a utility function ( $4 \mathrm{a})$ that represents the revenues from the different markets and the costs for generation, $C_{i, z}^{\mathrm{G}}$, and annualized investment costs, $C_{i, z}^{\mathrm{I}}$. Additional costs emerge from the transmission rights to offer capacity in a neighboring market zone with a CM. The revenues are the market volumes multiplied with the prices.

$$
\begin{gathered}
\max _{\chi_{i} \in \mathcal{X}_{i}} \Pi_{i}\left(\chi_{i}, \lambda_{\mathrm{MO}}\right)=\sum_{z \in \mathcal{Z}}\left[\sum_{t \in \mathcal{T}} W_{t} \cdot\left(\lambda_{z, t}^{\mathrm{e}}-C_{i, z}^{\mathrm{G}}\right) \cdot g_{i, z, t}+\lambda_{z}^{\mathrm{r}} \cdot r_{i, z}\right. \\
-C_{i, z}^{\mathrm{I}} \cdot \operatorname{cap}_{i, z}+\sum_{z^{\mathrm{sr}} \in \mathcal{Z}^{\mathrm{sr}}}\left(\lambda_{z^{\mathrm{sr}}}^{\mathrm{sr}}-\lambda_{z, z^{\mathrm{sr}}}^{\mathrm{sr}}\right) \cdot \operatorname{cap}_{i, z, z^{\mathrm{sr}}}^{\mathrm{sr}}
\end{gathered}
$$

${ }^{3} \mathrm{~A}$ discussion about the congestion rents from the energy-market and transmission rights for capacity used to justify investments in new transmission capacity can be found e.g. in [29]. 


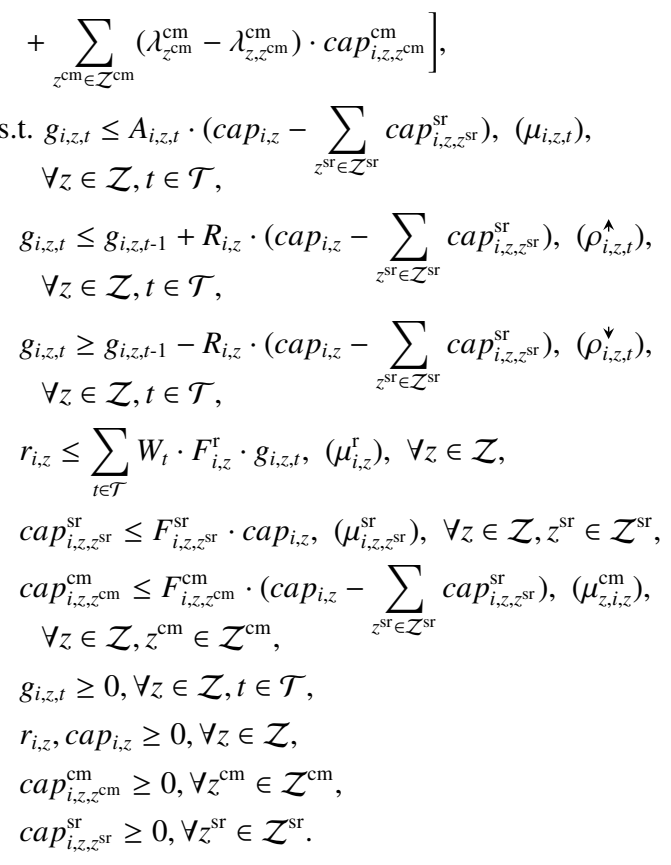

The energy output, $g_{i, z, t}$, is limited by technical characteristics including the ramping (4c)-(4d) and the overall installed capacity (4b). If capacity is sold exclusively to the SR, cap $p_{i, z, z^{\mathrm{sr}}}^{\mathrm{sr}}$, the capacity cannot be used for energy output or in another CM. The RES injection, $r_{i, z}$, is limited by the generated energy multiplied with a participation factor, $F_{i, z}^{\mathrm{r}}(4 \mathrm{e})$. Similar de-rating factors, $F_{i, z, z^{\mathrm{ss}}}^{\mathrm{sr}}, F_{i, z, z^{\mathrm{cm}}}^{\mathrm{cm}}$ are applied for the offered capacities to a CM (4f)-(4g). The offered capacities, $c_{a p}^{\mathrm{sr}}{ }_{i, z, z^{\mathrm{s}}}^{\mathrm{si}}, c_{i, z, z^{\mathrm{cm}}}^{\mathrm{cm}}$, are identified by the zone of investment, and the zone in which the CM is implemented. Note that in contrast to the SR (4f), the offered capacity to one capacity market is not limited by capacities offered to other capacity markets $(4 \mathrm{~g})$. In other words, capacity can be offered to multiple markets and the de-rating should take care of unintended effects.

\subsection{Consumer c}

The consumer, $c$, maximizes its consumer surplus, $\Pi_{c}$, across all markets based on the decision variables $\chi_{c}=\left(d_{z, t}^{\mathrm{e}}, l_{z, t}^{\mathrm{e}}, l_{z}^{\mathrm{r}}\right.$, $\left.d_{z^{\mathrm{cm}}}^{\mathrm{cm}}, l_{z^{\mathrm{cm}}}^{\mathrm{cm}}, l_{z^{\mathrm{sr}}}^{\mathrm{sr}}, g_{z^{\mathrm{s}}, t}^{\mathrm{sr}}\right) \in \mathcal{X}_{c}$. The consumer surplus is the served valued with the difference of the price cap and the clearing price. The demand on the markets for RES and the SR are assumed inelastic. Consequently, the decision variables are the unserved volumes, $l_{z}^{\mathrm{r}}, l_{z^{\mathrm{sr}}}^{\mathrm{sr}}$, that occur if the prices reaches

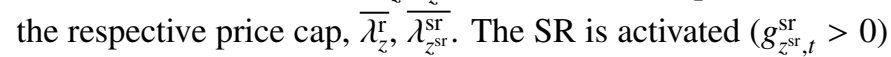
if the energy-based price reaches its price cap. The $\epsilon$ is set marginally small and ensures that the model choses the SR activation above ENS. The volume of activation is limited by the contracted volume of SR (5d).

For the energy and capacity market, sloped demand curve are modeled. The resulting price-sensitive demand levels, $d_{z, t}^{\mathrm{e}}$, $d_{z^{\mathrm{cm}}}^{\mathrm{cm}}$, and the unserved demand, $l_{z, t}^{\mathrm{e}}, l_{\mathrm{z}^{\mathrm{cm}}}^{\mathrm{cm}}$, must meet the demand curve (5c),(5b). We assume a simplification of the capacity demand curve by using a uniform slope. A model formulation with a piecewise downward-sloped is presented in [18]. The mathematical formulation yields the following equations:

$$
\begin{aligned}
& \max _{\chi_{c} \in \mathcal{X}_{c}} \Pi_{c}\left(\chi_{c}, \lambda_{\mathrm{MO}}\right)=\sum_{z \in \mathcal{Z}}\left[\left(\overline{\lambda_{z}^{\mathrm{r}}}-\lambda_{z}^{\mathrm{r}}\right) \cdot\left(D_{z}^{\mathrm{r}}-l_{z}^{\mathrm{r}}\right)\right] \\
& +\sum_{z^{\mathrm{sr}} \in \mathcal{Z}^{\mathrm{sr}}}\left[\left(\overline{\lambda_{z^{\mathrm{sr}}}^{\mathrm{sr}}}-\lambda_{z^{\mathrm{sr}}}^{\mathrm{sr}}\right) \cdot\left(D_{z^{\mathrm{sr}}}^{\mathrm{sr}}-l_{z^{\mathrm{sr}}}^{\mathrm{sr}}\right)\right] \\
& +\sum_{z \in \mathcal{Z}}\left[\sum_{t \in \mathcal{T}} W_{t} \cdot 1 / 2 \cdot\left(\overline{\lambda_{z}^{\mathrm{e}}}-\lambda_{z, t}^{\mathrm{e}}\right) \cdot\left(d_{z, t}^{\mathrm{e}}+\underline{D_{z, t}^{\mathrm{e}}}\right)\right] \\
& +\sum_{z^{\mathrm{sr}} \in \mathcal{Z}^{\mathrm{sr}}}\left[\sum_{t \in \mathcal{T}} W_{t} \cdot\left(\lambda_{z^{\mathrm{sr}}, t}^{\mathrm{e}}-\left(\overline{\lambda_{z^{\mathrm{sr}}}^{\mathrm{e}}}-\epsilon\right)\right) \cdot g_{z^{\mathrm{sr}}, t}^{\mathrm{sr}}\right] \\
& +\sum_{z^{\mathrm{cm}} \in Z^{\mathrm{cm}}}\left[1 / 2 \cdot\left(\overline{\lambda_{z^{\mathrm{cm}}}^{\mathrm{cm}}}-\lambda_{z^{\mathrm{cm}}}^{\mathrm{cm}}\right) \cdot\left(d_{z^{\mathrm{cm}}}^{\mathrm{cm}}+\underline{D_{z^{\mathrm{cm}}}^{\mathrm{cm}}}\right)\right], \\
& \text { s.t. } d_{z^{\mathrm{cm}}}^{\mathrm{cm}}+l_{z^{\mathrm{cm}}}^{\mathrm{cm}}=\lambda_{z^{\mathrm{cm}}}^{\mathrm{cm}} / M_{z^{\mathrm{cm}}}^{\mathrm{cm}}-B_{z^{\mathrm{cm}}}^{\mathrm{cm}} / M_{z^{\mathrm{cm}}}^{\mathrm{cm}},\left(\omega_{z^{\mathrm{cm}}}^{\mathrm{cm}}\right), \forall z^{\mathrm{cm}} \in \mathcal{Z}^{\mathrm{cm}} \text {, }
\end{aligned}
$$

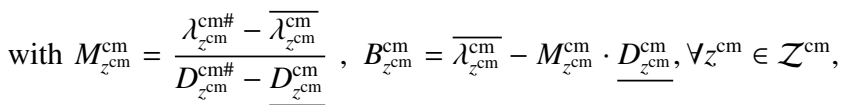

$$
\begin{aligned}
& d_{z, t}^{\mathrm{e}}+l_{z, t}^{\mathrm{e}}=\lambda_{z, t}^{\mathrm{e}} / M_{z}^{\mathrm{e}}-B_{z, t}^{\mathrm{e}} / M_{z}^{\mathrm{e}},\left(\omega_{z, t}^{\mathrm{e}}\right), \quad \forall z \in \mathcal{Z}, t \in \mathcal{T}, \\
& \text { with } B_{z, t}^{\mathrm{e}}=\lambda_{z}^{\mathrm{e} \#}-M_{z}^{\mathrm{e}} \cdot D_{z, t}^{\mathrm{e}}, \forall z \in \mathcal{Z}, t \in \mathcal{T} \text {, } \\
& g_{z^{\mathrm{s}}, t}^{\mathrm{sr}} \leq D_{z^{\mathrm{sr}}}^{\mathrm{sr}}-l_{z^{\mathrm{sr}}}^{\mathrm{sr}}, \forall z^{\mathrm{sr}} \in \mathcal{Z}^{\mathrm{sr}}, t \in \mathcal{T}, \\
& g_{z^{\mathrm{r}}, t}^{\mathrm{sr}}, z_{z^{\mathrm{sr}}}^{\mathrm{sr}} \geq 0, \forall z^{\mathrm{sr}} \in \mathcal{Z}^{\mathrm{sr}} \text {, } \\
& l_{z}^{\mathrm{r}} \geq 0, \forall z \in \mathcal{Z}, \\
& d_{z^{\mathrm{cm}}}^{\mathrm{cm}}, l_{z^{\mathrm{cm}}}^{\mathrm{cm}} \geq 0, \forall z^{\mathrm{cm}} \in \mathcal{Z}^{\mathrm{cm}}, \\
& d_{z, t}^{\mathrm{e}}, l_{z, t}^{\mathrm{e}} \geq 0, \forall z \in \mathcal{Z}, t \in \mathcal{T} \text {. }
\end{aligned}
$$

\section{Case Study: Three Interconnected Markets}

This section discusses the case study for which the proposed model is applied. First, the scenario-independent data and assumptions are presented. This is followed by an introduction to the compared scenarios. We distinguish a reference scenario and three different scenarios that built up logically. Focus is put on implicit and explicit cross-border participation and the de-rating of the interconnection capacity.

The proposed model is suited for multiple market zones. However, we focus on three market zones in order to simulate the three different market designs, energy-only market (EOM), $\mathrm{SR}$, and capacity market. The objective is to highlight observations that can be transferred to general policy guidelines for harmonization and the setup of cross-border participation. Considering other combinations of CMs, or choosing market zones with different available technologies, or eventually simulating the European market area could be a valuable application of the proposed model in future studies.

\subsection{Data and Assumptions}

Three market zones (A, B \& C) create an interconnected market area. Fig. 3 visualizes the three market zones and the available interconnections used for the exchange of energy and capacity. The three market zones differ in peak demand and total energy demand. Markets A and B are relatively small compared to market $\mathrm{C}$, which is about three times the size of $\mathrm{A}$ or B.

We assume that the RES target is equal in all zones. In each zone, $40 \%$ of the energy must be generated from domestic RES. There is no trading of RES certificates across borders. 
A shared market for RES certificates would reduce the need of RES capacities as they can be installed in the most favorable markets. An even higher target, pointing at future policy targets, would emphasize the role of capacity markets because of decreasing energy prices and increased dependencies on price spikes. In that case, the conclusions on the inefficiencies in Section 4 would remain valid or are even emphasized.

In each zone, a low demand flexibility in form of a low inverse price-elasticity of $M_{z}^{\mathrm{e}}=-40 € / \mathrm{MWh}^{2}$ and a reference price $\lambda_{z}^{\mathrm{e} \#}=55 € / \mathrm{MWh}$ is assumed. The reference price is assumed a weighted average price for energy given the conventional technologies and their variable cost. Moreover, the demand flexibility is the same for all time steps. The impact of increasing price elasticities on the generation mix is discussed in [20].

An increased flexibility of the demand side, i.e., a flatter energy demand curve, could also lead to lower capacity demand levels. We have chosen a low flexibility because in current practice those contributions are only limited taken into account. During the assessment of the capacity demand, they are mostly assumed hard to predict. An additional study on the impact of demand flexibility would be very valuable, especially focusing on peak demand flexibility.

In between all market zones, an arbitrary interconnection of $3000 \mathrm{MW}$ is assumed. For this case study, we assume that the interconnection capacity is fixed and the IO does not take transmission investment decisions. The complete installed interconnection capacity can be used for energy trading in both directions. The interconnections also facilitate the cross-border participation of capacity in a CM if applicable. In an equilibrium, if the de-rated interconnection capacity is binding for cross-border participation, the capacity congestion rents, $\lambda_{z z \mathrm{~cm}}^{\mathrm{cm}}$, have the same value as the capacity price, $\lambda_{z^{\mathrm{cm}}}^{\mathrm{cm}}$. Consequently, the additional revenues does not end up with the generators in the neighboring market, but with the interconnector. A followup case study might therefore take into account investments in interconnection capacity that follow market signals. A similar case study on changing interconnection capacities is presented in [19].

Three conventional technologies (Base, Mid, Peak) and two RES technologies $(P V$, Wind $)$ are available in each market zone. Each technology is represented by an individual generator $G_{i}{ }^{4}$. The input parameters for the technologies in Market A are given in Table 2. Each technology of the same type is assumed to have the same ramping capabilities in all zones. However, we assume a slight difference in variable cost, $C^{\mathrm{G}}$, and annualized investment costs, $C^{\mathrm{I}}$, among the markets. These cost differences can for instance be related to differences in taxation policy, primary fuel markets, level of competition, etc. The difference is assumed symmetrically $5 \%$ relative to Market $\mathrm{A}$ and given in Fig 3.

The demand, wind and solar profiles are taken from Belgium, The Netherlands, and GB for the year 2015. The demand profiles are obtained from the ENTSO-E transparency platform [30]. The solar and wind profiles are taken from the EMHIRES

\footnotetext{
${ }^{4}$ A portfolio approach of multiple technologies in one or more market zones is not part of this study. This could be an interesting extension of case study.
}

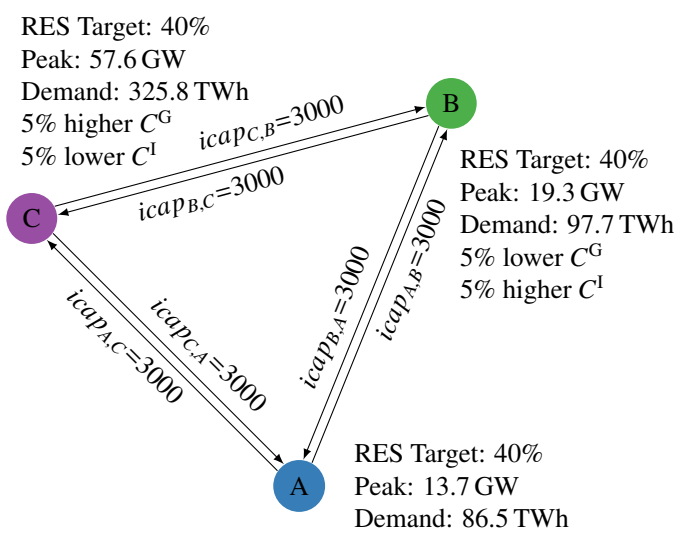

Figure 3: Model set-up with three markets and interconnection capacities

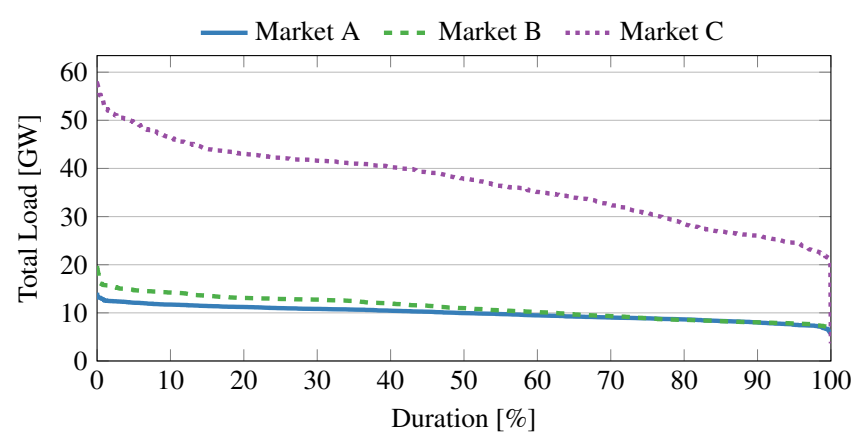

Figure 4: Load Duration Curves (based on 30 representative days)

datasets [31, 32]. In order to maintain computational feasibility, 30 representative days are selected based on [33]. Each representative time step is associated with a weight, $W_{t}$. The resulting load duration curves are displayed in Fig. 4.

\subsection{Scenarios}

The case study defines a reference scenario and three successive scenarios. The last scenario has two subparts distinguishing implicit and explicit cross-border contribution. Table 3 gives an overview of the scenario and the associated assumptions. The following sections give a motivation for each scenario. The numerical values of the target capacity demand presented in the Table 3 are a result of the energy-only market scenario, EOM, and are discussed in details in Section 4.1.

\subsubsection{Reference scenario: Central planning - REF}

The reference scenario, $R E F$, forms the baseline for the following scenarios. In this scenario, an EOM without a price cap and a market for RES certificates define the market setting. For our given case study, the outcome of this scenario coincides with a cost minimization as done by a central planner. The result yields minimum cost and no ENS. In an equilibrium, the energy price can reach sufficiently high price spikes in the hour, which is most constraining for the system combining all demand and RES profiles. It is sufficient to ensure cost recovery of all generators. In studies assuming a more price-elastic demand or storage applications, ENS might already be avoided 
Table 2: Input parameters for case study (based on [34, 35])

\begin{tabular}{l|ccc|ccc|ccc}
\hline $\begin{array}{l}\text { Type } \\
i \in \mathcal{N}\end{array}$ & $\begin{array}{c}C_{i, A}^{\mathrm{G}} \\
{[€ / M W h]}\end{array}$ & $\begin{array}{c}C_{i, A}^{\mathrm{I}} \\
{[€ / M W \text { year }]}\end{array}$ & $\begin{array}{c}R_{i, z} \\
{[\% / h]}\end{array}$ & $\sum W_{t} A_{i, A, t}$ & $\begin{array}{c}\sum W_{t} A_{i, B, t} \\
{[\text { h/year }]}\end{array}$ & $\sum W_{t} A_{i, C, t}$ & $F_{i, z}^{\mathrm{r}}$ & $F_{i, z, z^{\mathrm{sr}}}^{\mathrm{sr}}$ & $F_{i, z, z^{\mathrm{cm}}}^{\mathrm{cm}}$ \\
\hline Base & 36 & 138000 & 50 & 8760 & 8760 & 8760 & 0 & 1 \\
Mid & 53 & 82000 & 80 & 8760 & 8760 & 8760 & 0 & 1 \\
Peak & 76 & 59000 & 100 & 8760 & 8760 & 8760 & 0 & 1 \\
\hline PV & 0 & 110000 & - & 1131 & 1015 & 866 & 1 & 0 \\
Wind & 0 & 76500 & - & 2040 & 1916 & 1346 & 1 & 0 \\
\hline
\end{tabular}

Table 3: Scenario design for the different market settings

\begin{tabular}{|c|c|c|c|c|c|}
\hline Scenario & Markets & $\begin{array}{c}\text { Price cap } \\
\text { energy market }\end{array}$ & $\begin{array}{c}\text { RES } \\
\text { target }\end{array}$ & $\begin{array}{l}\text { Target capacity } \\
\text { demand }[G W]\end{array}$ & $\begin{array}{l}\text { Cross-border } \\
\text { contribution }\end{array}$ \\
\hline$R E F$ & \multirow{2}{*}{ all EOM } & Not applicable & \multirow{5}{*}{$40 \%$} & & \multirow{2}{*}{ Not applicable } \\
\hline EOM & & \multirow{4}{*}{$3000 € / \mathrm{MWh}$} & & Not applicable & \\
\hline MIX & A: EOM; B: SR; C: CM & & & B: $0.026 ; C: 47.1$ & \multirow{2}{*}{ Implicit } \\
\hline$c C M_{i m}$ & \multirow{2}{*}{ all CM } & & & A: $9.9 ; \mathrm{B}: 12.1 ; \mathrm{C}: 47.1$ & \\
\hline$c C M_{e x}$ & & & & A: $12.9 ; \mathrm{B}: 16.2 ; \mathrm{C}: 48.2$ & Explicit \\
\hline
\end{tabular}

without prices exceeding the price cap introduced in the next scenario.

\subsubsection{Scenario 1: Energy-only markets with price caps -EOM}

The first scenario, EOM, is set up as three coupled energyonly markets. It only differs from the reference scenario, $R E F$, in the implementation of a price cap in each energy market, $\overline{\lambda_{z}^{\mathrm{e}}}$, equal to $3000 € / \mathrm{MWh}$. Additionally, the results of this scenario are used to define the capacity demand curves for the SR and the centralized capacity market based on the occurring ENS for the consecutive scenarios.

\subsubsection{Scenario 2: Patchwork of capacity mechanisms - MIX}

The second scenario, $M I X$, reflects the current developments in the European electricity market landscape. Individual market zones implement CMs that are not necessarily harmonized.

We assume that market B decides to implement SR (Fig. 1c) because of observed ENS in EOM. The system operator uses the result of EOM for determining the necessary SR volume to avoid ENS. The volume, $D_{B}^{\mathrm{sr}, \mathrm{im}}$, is defined as the gap between the residual peak demand and the installed conventional capacity in market B in scenario EOM as described by Eq. (6). The residual peak demand is defined as the maximum demand reduced by the generation from RES. The demand implicitly takes into account possible contributions from imports during the peak hours. As such, the sizing of the SR requires perfect foresight on RES and import contribution. The volume is calculated as follows:

$D_{z}^{\mathrm{sr}, \mathrm{im}}=\max _{t}\left(d_{z, t}^{\mathrm{e}}+l_{z, t}^{\mathrm{e}}-\sum_{i \in\{P V, \text { Wind }\}} g_{i, z, t}\right)-\sum_{i \in \mathcal{N}} \operatorname{cap}_{i, z}$.

The price cap for the SR, $\overline{\lambda_{z \mathrm{sr}}^{\mathrm{sr}}}$, is set equal to the CONE which is assumed the investment cost of the Peak technology $C_{\text {Peak,B}}^{\mathrm{I}}$.

Market $\mathrm{C}$ also observes ENS in EOM and introduces a capacity market (Fig. 1d). The demand curve of the capacity market in market $\mathrm{C}$ is defined by two points. The target demand,

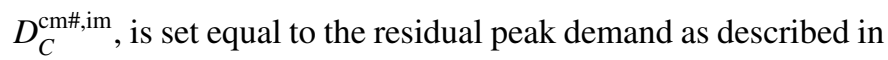
Eq. (7). In addition, this demand takes into account the contribution from imports during the peak hours. The residual peak demand is calculated as follows:

$D_{z}^{\mathrm{cm} \#, \mathrm{im}}=\max _{t}\left(d_{z, t}^{\mathrm{e}}+l_{z, t}^{\mathrm{e}}-\sum_{i \in\{P V, W i n d\}} g_{i, z, t}\right)$.

The target price, $\lambda_{z^{\mathrm{cm}}}^{\mathrm{cm} \#}$ is set to the Net CONE, which is assumed $40 \%$ of the CONE in market $\mathrm{C}, C_{\text {Peak,C }}^{\mathrm{I}}$. The minimum and maximum demand are symmetrical to the target demand at $97 \%$ respectively $103 \%$. The price cap is set to the CONE.

Market A remains an EOM. Other combinations of market designs are possible but not part of this case study. This scenario serves to highlight inefficiencies of non-harmonized CMs, which could also occur for other combinations.

\subsubsection{Scenario 3: Harmonized capacity market - cCM}

The last scenario, $c C M$, represents a harmonized approach for CMs. In contrast to $M I X$, each market zone implements the same CM, a capacity market. Explicit cross-border participation is allowed to the extent as the interconnection capacity is de-rated by the factor, $F_{z, z^{\mathrm{cm}}}^{\mathrm{cm}}$. We determine the target capacity demand $\lambda_{z^{\mathrm{cm}}}^{\mathrm{cm}}$ either considering the import flows or not. Again, the values are determined based on the results of the second scenario, EOM, as this scenario is assumed the motivation for the implementation of capacity markets.

First, we assume that the residual demand can be covered by a combination of domestic and non-domestic generation. The capacity demand, $D_{z}^{\mathrm{cm} \# \text {,ex }}$, is set to the expected peak demand of the zone which can be covered both by domestic and nondomestic capacity in a market with explicit cross-border participation. We denote this sub-scenario $c C M_{e x}$. We exclude the import during peaks. The residual peak demand, $D_{z}^{\mathrm{cm} \# \text {,ex }}$, is calculated as follows:

$D_{z}^{\mathrm{cm} \#, \mathrm{ex}}=\max _{t}\left(d_{z, t}^{\mathrm{e}}+l_{z, t}^{\mathrm{e}}-\sum_{i \in\{P V, \text { Wind }\}} g_{i, z, t}+\sum_{z^{\prime} \in \mathcal{Z}} f_{z^{\prime}, z, t}^{\mathrm{e}}\right)$.

Second, we assume that the residual demand implicitly takes into account contributions from capacity in neighboring markets reflected in the energy flows during peak demand. This

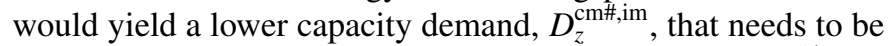

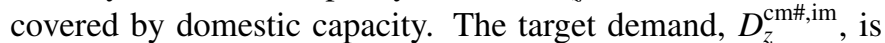
defined by Eq. (7). We denote this sub-scenario $c C M_{i m}$. 

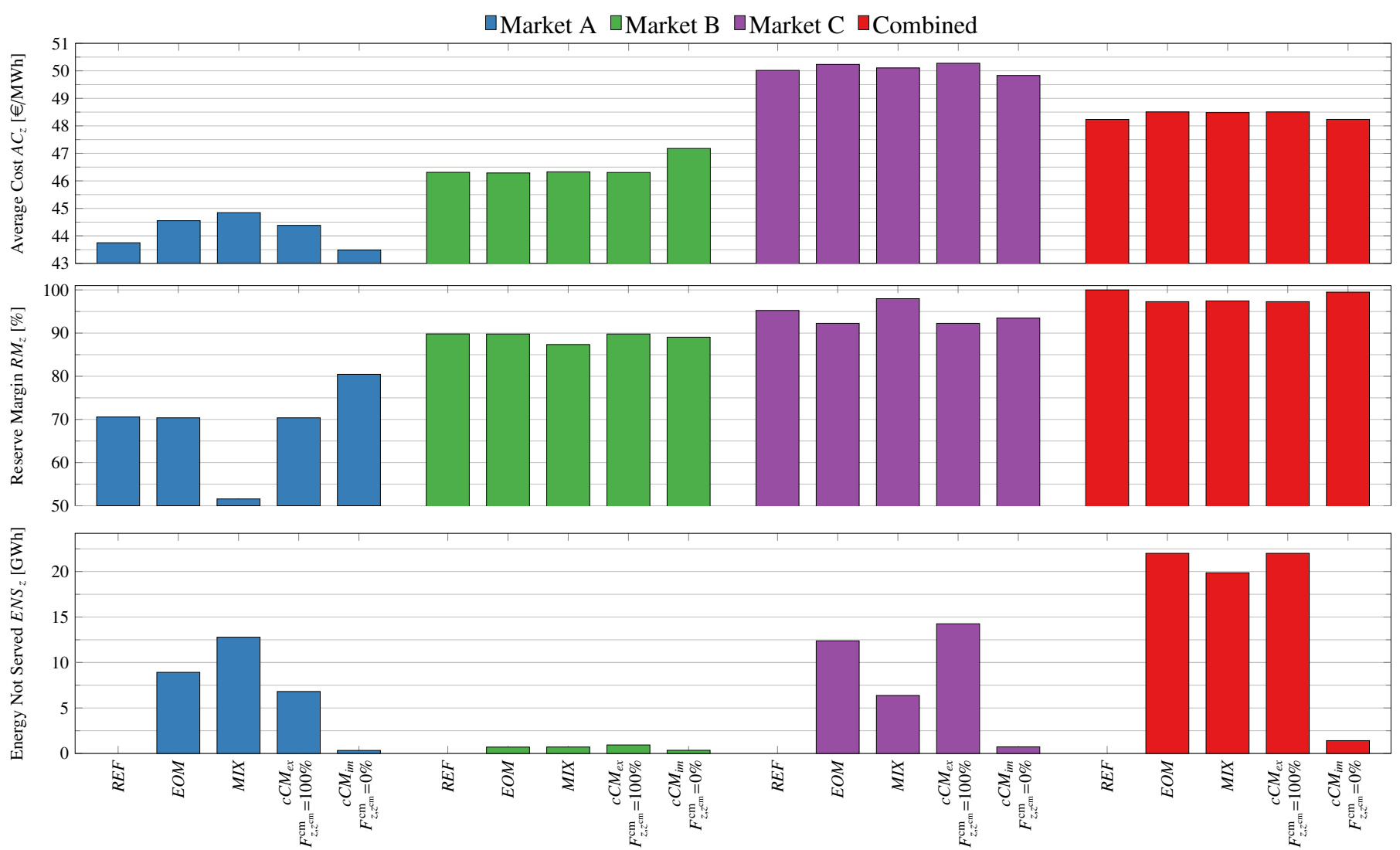

Figure 5: Comparison of scenarios grouped per market

For both sub-scenarios, the target prices and price caps depend for each market zone on the CONE, i.e., the fixed cost of the Peak technology, $C_{P e a k, z}^{\mathrm{I}}$. The Net CONE is assumed $40 \%$ of the CONE in each market.

\section{Results and Discussion}

In this section, we discuss the results of the case study. The first part focuses on the comparison of the scenarios. The second part discusses the impact of cross-border participation and the de-rating of the interconnection. The scenarios are compared along the average cost per energy, the reserve margins, and the changes in energy flows and installed capacities in the three market zones A, B and C.

\subsection{Impact of harmonizing capacity mechanisms}

We first compare the different market settings represented in the scenarios. The description of the results is followed by a discussion.

\subsubsection{Comparison of market settings}

In order to assess the scenarios, the average cost for served electricity, the reserve margin and the ENS are compared. The average cost of electricity, $A C_{z}$, describes the total cost faced by the consumer across all markets (energy, RES, availability) divided by the served demand. Additionally, the total cost includes the cost of ENS valued by a moderate Value of Lost
Load (VoLL) of $10000 € / \mathrm{MWh}$. The average cost is reported per market zone or combined for the whole system. In the combined case, the total cost are divided by the total served demand. Formally, the average cost is calculated as follows:

$$
\begin{gathered}
A C_{z}=\frac{\lambda_{z}^{\mathrm{r}} \cdot\left(D_{z}^{\mathrm{r}}-l_{z}^{\mathrm{r}}\right)+\lambda_{z}^{\mathrm{sr}} \cdot\left(D_{z}^{\mathrm{sr}}-l_{z}^{\mathrm{sr}}\right)+\lambda_{z}^{\mathrm{cm}} \cdot d_{z}^{\mathrm{cm}}}{\sum_{t \in \mathcal{T}} W_{t} \cdot d_{z, t}^{\mathrm{e}}} \\
+\frac{\sum_{t \in \mathcal{T}} W_{t} \cdot \lambda_{z, t}^{\mathrm{e}} \cdot d_{z, t}^{\mathrm{e}}+\sum_{t \in \mathcal{T}} W_{t} \cdot \operatorname{VoLL} \cdot l_{z, t}^{\mathrm{e}}}{\sum_{t \in \mathcal{T}} W_{t} \cdot d_{z, t}^{\mathrm{e}}} \cdot[€ / \mathrm{MWh}]
\end{gathered}
$$

The reserve margin, $R M_{z}$, is calculated as residual peak demand divided by the installed conventional capacity. The combined reserve margin of all market zones is based on the aggregated residual demand of the system. Note that, this is not necessarily the same as the sum of individual residual peak demands. Formally, the reserve margin is calculated as follows:

$R M_{z}=\frac{\max _{t}\left(d_{z, t}^{\mathrm{e}}+l_{z, t}^{\mathrm{e}}-\sum_{i \in\{P V, \text { Wind }\}} g_{i, z, t}\right)}{\sum_{i \in \mathcal{N}} \operatorname{cap}_{i, z}-\sum_{i \in\{P V, \text { Wind }\}} \operatorname{cap}_{i, z}} \cdot 100 \% . \quad[\%]$

The ENS, $E N S_{z}$, is calculated as follows:

$E N S_{z}=\sum_{t \in \mathcal{T}} W_{t} \cdot l_{z, t}^{\mathrm{e}} \cdot[\mathrm{MWh}]$

The top row of Fig. 5 shows the average cost, $A C_{z}$, for all market zones. On the X-axis, the different scenarios are listed grouped per market zone. The middle row of Fig. 5 shows the 
reserve margin, $R M_{z}$. The bottom row of Fig. 5 displays the ENS, $E N S_{z}$, for each market. We evaluate the scenarios using these three indicators in combination. In order to analyze the mpact on the operation of the system, the energy flows over the interconnections is displayed in Fig. 6a and the changes of the generation mix is shown in Fig. 6 b.

From a system perspective, the reference scenario, $R E F$, shows the expected outcome. It achieves a system reserve margin of $100 \%$, the ENS is zero, and the combined average costs are lowest. A 100\% reserve margin in the individual markets is not targeted. This indicates the benefits of market coupling. Generation technologies are used and shared optimally in terms of energy, and implicitly in terms of capacity among all market zones. The cost differences among the markets are caused by the demand profiles and different the variable and fixed cost.

In case of energy-only markets with a price cap, EOM, the generation mix results in ENS in all markets (bottom Fig. 5). Due to the price cap, revenues from the EOM are not sufficient ente incentives for adequate investment. The combined reserve margin decreases below $100 \%$, because of a reduction of installed capacity mainly in market C. Fig. 6a shows the adjusted energy flows across the interconnections, which causes markets $\mathrm{A}$ and $\mathrm{B}$ facing ENS. Based on scenario EOM, market B implements few SR of $97 \mathrm{MW}$ in $M I X$. Market C puts a capacity market in place with a target demand of $45.52 \mathrm{GW}$.

Surprisingly, the combination of CMs, i.e., scenario MIX, yields worse results. Although market B implements SR, the ENS in market B is higher than in EOM. This can be explained by the fact that both CMs in B and C lead to a shift of capacity from market A to market C (Fig. 6b). Market A's capacity is reduced due to increased imports. Market C's generation mix changes due to a partial shift from energy- to capacity-based remuneration. In combination, this results in reduced flows from market A in times of scarcity in market B. As such, the sizing of the SR should anticipate on these changes, which highlights one of the challenges when introducing SR. Market $\mathrm{C}$ is not negatively affected as its capacity market leads to a domestic reserve margin above $100 \%$.

The two last sub-scenarios, $c C M_{e x}$ and $c C M_{i m}$, show very different outcomes, although both scenarios implement a harmonized approach of capacity markets. The main difference originates from the determination of the demand curve and the allowance of cross-border participation.

In case of explicit cross-border participation, $c C M_{e x}$, the capacity demand is higher, but also the supply of capacity is higher in each market because the additional non-domestic capacity can participate without de-rating. Consequently, prices for capacity remain very low and the share of remuneration rom capacity is limited. The generation mix is hardly affected and shows similar capacity changes as in EOM (see Fig. 6b). The purpose of the capacity markets is not fully achieved, as there is ENS. In the current situation, the contribution of availability from other markets is overrated. The assumption that capacity can be offered in multiple capacity markets in parallel leads to a situation of capacity shortage during scarcity. The de-rating of $100 \%$ is a too optimistic assumption. This has the consequence that the system reserve margin drops below $100 \%$.
The interaction of offering capacity in multiple markets and the de-rating is discussed in more detail in Section 4.2.

The case of implicit cross-border participation, $c C M_{i m}$, which does not rely on participation from non-domestic capacity, shows a different result. Due to the limitation of capacity supply to the domestic market, the scarcity signal is transferred from the energy to the capacity market. The value of availability is shifted to the capacity price. Therefore, the energy prices are reduced and reflect only the variable costs; also during peak demands. Consequently, the shift of remuneration from energy to capacity also affects the choice of technologies (Fig. 6b). Indirectly, this shift also affects RES. The reduction of Wind capacity is because energy prices are lower during scarcity. While it was beneficial in the previous scenarios to install more capacity, curtail if necessary and benefit from high prices shared across the zones, this incentive is gone and the capacity is reduced. This effect is also discussed in detailed in [18].

In terms of average cost, reserve margin, and ENS this scenario, $c C M_{i m}$, shows similar results as the optimal scenario, $R E F$, yet, the generation mixes are different and consequently also the average costs in the individual markets differ. Note again, that the scenario relies on correct assumptions about the imports during the scarcity hours to parametrize the capacity demand curve. A sensitivity analysis on this assumption is done in Section 4.2.

\subsubsection{Discussion}

The results of our case study show that the configuration of market designs in the three markets has only limited impact on the average cost given the used parameters. Therefore, this result is not generalizable. However, closer analyses of the results reveal that in terms of changing generation mixes and levels of reserve margins differences emerge from the market designs. These effects are not directly dependent on the chosen parameters but on the analyzed market designs and are therefore of more interest.

Given the assumed approach to determine the capacity demands from EOM to $M I X$, a resulting patchwork of CMs yields more ENS. At the same time, it yields highest average costs. The result shows that the determination of the capacity demand cannot be done independent from adjacent markets and their choice of $\mathrm{CM}$ and the resulting cross-border contribution. However, the estimation of the capacity demand used in the scenario $M I X$ is very simplified and based on the outcome EOM.

Consequently, when considering implicit cross-border contribution, the assumption is made that under the new market schemes this contribution stays unchanged. This leads to wrong estimates with negative effects, like increased cost or ENS. Both markets, i.e., those with and those without a CM, can experience these effects. Nevertheless, this does not exclude the possibility that there might be situation for which it is beneficial to make best use of different CMs. However, this requires a coherent and coordinated approach to make best use of cross-border participation as described in [19].

Interestingly, the two scenarios with harmonized capacity markets show very different results. The decision for an implicit or explicit participation of non-domestic capacity should 


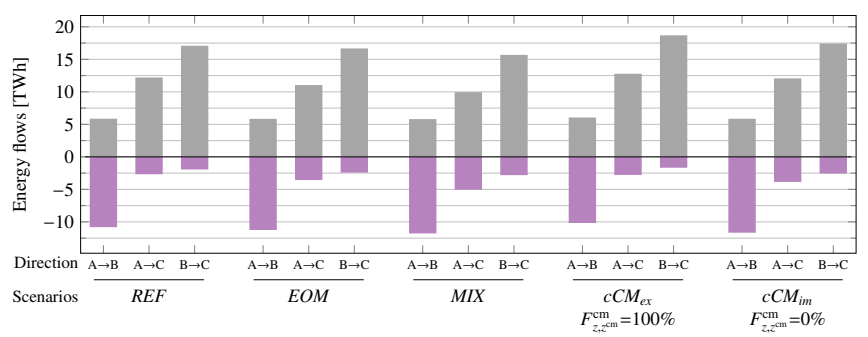

(a) Flows of energy over the interconnection

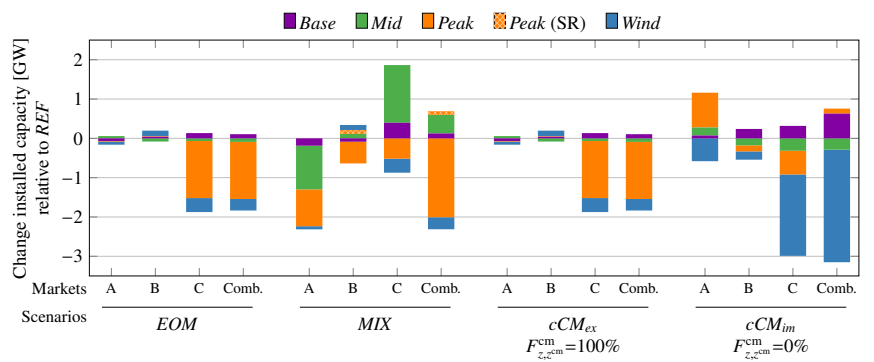

(b) Capacity change relative to the reference case

Figure 6: Results for energy flows and installed capacities and generation mix in mind.

Given our case study, an explicit participation model yields in similar results as EOM. Although the capacity demand is higher, the cross-border capacity supply tends to lead to overscarcity during peak demands. Crucial for a good result in terms of cost and ENS is the de-rating of the cross-border participation that needs to limit the participation based on the estimated energy contribution during peak demand.

An implicit participation, assuming that the contribution is estimated correctly, leads to high prices on the capacity market determined by domestic capacity. Consequently, energy prices echoing the variable cost of the price-setting technology are possible. Because of changing RES capacities, technologies that are more flexible might be necessary. In the case study, these shifts yield a different generation mix. Crucial for a good result is the estimation of the capacity demand that implicitly assumes the contribution during peak demand. For both participation models, these crucial estimates are worth a closer as-

\subsection{Impact of estimated cross-border participation}

After assessing the different market settings, we aim at quantifying the cost of lack of coordination or wrong estimation of possible contribution for a given scenario. To this extent, a senmarket zones have agreed on a common CM, namely a capacity market in each of the market zones. In a next step, there are two options to determine the capacity demand. This can be either done assuming implicit participation or explicit participation. of the cross-border contribution, the results reveal some potential pitfalls. Same as in the previous section, the description of the results is followed by a discussion.

\subsubsection{Implicit and explicit cross-border participation}

The sensitivity analysis on the de-rating of the cross-border participation is done for harmonized capacity markets. Again, we compare the average cost, $A C_{z}$, the reserve margin, $R M_{z}$, and the ENS, ENS $z$. The results are shown for the combined system in Fig. 7. The results for the scenarios $R E F$ and the
For the case of an implicit participation, the de-rating factor, $F_{z, z^{\mathrm{cm}}}^{\mathrm{cm}}$, is increased, i.e., more and more non-domestic capacity can participate although the contribution is assumed to be already taken into account in the capacity demand. The coinciding scenario with implicit participation in the previous section, $c C M_{\text {im }}$, equals the $0 \%$ and is located at the left in the graphs. Obviously, an implicit model does not foresee cross-border participation, but relaxing the de-rating factor would be the same as assuming that the implicit contribution was increasingly overestimated.

The results of the case study show that already for a small deviation from the de-rating of $0 \%$, the reserve margin drops below $100 \%$ (Fig. 7b) resulting in ENS (Fig. 7c). This comes with increased average costs (Fig. 7a). This can be explained with too much capacity offered compared to the low capacity demand already taking into account implicit cross-border participation. The consequence is a low or zero price for capacity and increasing energy prices, eventually hitting the price cap. At that point, in the case study at $30 \%$, the results for $c C M_{i m}$ are equal to those of $E O M$. The total installed capacity decreases to the level of the scenario EOM. It remains at that level resulting in the same results for the reported indicators.

In case of the explicit participation, we can observe two deviation because of wrongly estimating the cross-border participation. Starting from $100 \%$, the de-rating factor of the interconnection, $F_{z, z^{\mathrm{cm}}}^{\mathrm{cm}}$, is decreased, i.e., the contribution of nondomestic capacity is reduced. The coinciding scenario with explicit participation in the previous section, $c C M_{e x}$, equals the $100 \%$ and is located at the right end in the graphs. Between the values of $60 \%$ and $100 \%$ for our case study, the contribution is overestimated. The results show the same outcome as in the case of implicit participation with cross-border participation. The same reasoning can be applied.

Below a de-rating of $20 \%$, we observe an opposite behavior because the cross-border contribution is underestimated due to a too conservative de-rating. Because capacities from neighboring countries are not utilized to their full value to cover the capacity and energy demands, inefficient investment takes place that leads to an reserve margin above $100 \%$ (Fig. 7b). Consequently, the ENS is reduced to zero (Fig. 7c). However, this comes with a cost increase (Fig. 7a).

In between $20 \%$ and $60 \%$, the de-rating yields some intermediate results. Note that in our case study a unified de-rating is 


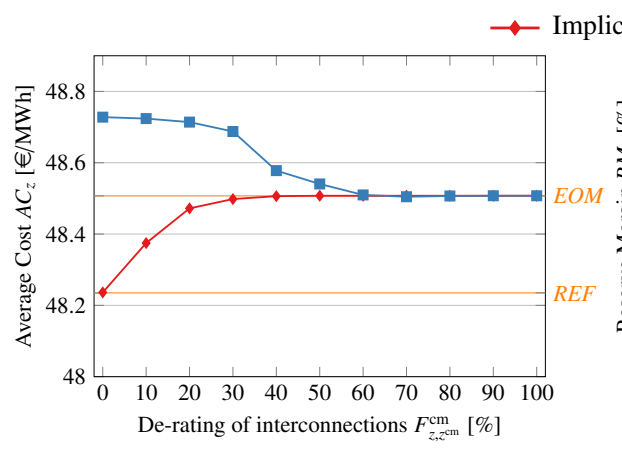

(a) Average cost of electricity

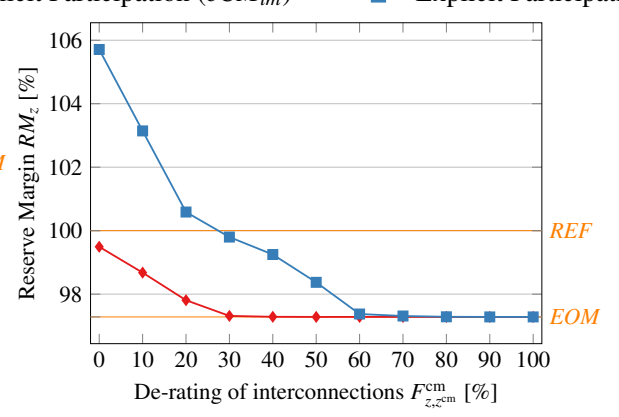

(b) Reserve margin

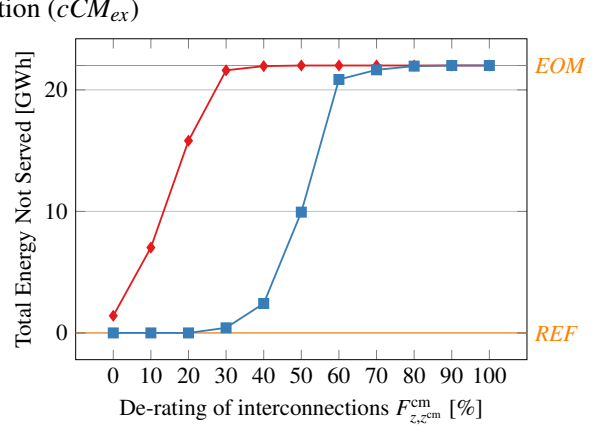

(c) Energy Not Served

Figure 7: Results for the combined system dependent on changing de-rating of the interconnection capacity

applied, e.g., the interconnection $\mathrm{A} \rightarrow \mathrm{B}$ is de-rated in the same way as $\mathrm{B} \rightarrow \mathrm{A}$. This means that capacity could be exchanged in both directions to fulfill capacity demands. If the de-rating should account for the energy flows during scarcity situation, a more detailed approach would be necessary.

For example, if the optimal flows of the scenario $R E F$ would be baseline, the de-rated cross-border participation should be limited for the three interconnections to the following values: $F_{A, C}^{\mathrm{cm}}=7.44 \%, F_{B, A}^{\mathrm{cm}}=3.81 \%, F_{B, C}^{\mathrm{cm}}=61.30 \%$. The opposite directions should be de-rated to $0 \%$. However, this would assume that the energy-based flows would not change which again is not a given. This underlines the need for a harmonized approach to a capacity market, and more important to a common approach for generation adequacy assessments and for an efficient estimation of cross-border participation.

\subsubsection{Discussion}

The results from the de-rating of interconnections emphasize the need for harmonization. This is independent of the chosen method to facilitate cross-border participation. There is a possibility to over- or underestimate the contribution of nondomestic capacity in a $\mathrm{CM}$, which has negative consequences for the average cost, reserve margin and ENS.

Underestimating the contribution of non-domestic capacity leads to an inefficient over-investment in capacities, which leads to an increase of the average cost. This is the result of either derating interconnection capacity too conservative or setting the capacity demand too high.

Overestimating the contribution of non-domestic capacity increases the chance of ENS because investment of capacity is too low to reach a reserve margin of $100 \%$. Such an overestimation of cross-border participation is the result of a too optimistic assessment leading to a double counting of available capacity.

The chance of wrongly estimating the cross-border participation is higher if markets do this assessment individual. A common and harmonized approach is recommended. A common de-rating of the interconnections or a common estimation of the implicit demand identifies the direction of cross-border participation that also reflects the energy flows during scarcity situation. A major challenge, for both the implicit and explicit participation, is the estimation of these resulting energy flows during the determination of the capacity demand and the derating. As transmission system operators are typically assumed risk-averse, they would prefer a more conservative approach. This could lead to higher cost for consumers.

\section{Conclusions}

Next to the general discussion on the need for capacity mechanisms (CMs), the harmonization of CMs and the facilitation of cross-border participation is currently on the agenda of policy makers. Two methodologies for cross-border participation are discussed. An implicit participation already takes into account contributions from neighboring markets during the determination of the capacity demand. Alternatively, an explicit participation allows non-domestic capacity to participate directly in the CM that reflects the total demand for capacity. In this paper, a market model based on non-cooperative game theory is proposed in order to assess the impact of the different methodologies of cross-border participation and related challenges.

Different market settings for three market zones are examined for a specific set of market parameters. In the presented case study, a patchwork of CMs shows highest average cost, at the same time the highest volume of Energy Not Served (ENS) and lowest reserve margin. This is, however, the result of a very simplistic approach to account for cross-border contributions under changing market settings. Because of investors' reactions to the introduction of CMs, these changes need to be taken into account a priori during the determination of the capacity demand. In reality, this requires an ongoing adaptation of the market parameters as response to surrounding markets.

The results for a harmonized approach of CMs show that there is a chance of under- or overestimating the cross-border participation, which leads to economic inefficiencies. These are over-investments resulting in increased costs because of too conservative assumptions about the non-domestic contribution. In turn, insufficient reserve margins because of double counting of capacity across multiple markets result in too low capacitybased remuneration and a decrease of installed capacity.

The case study points out that a common and harmonized approach to represent non-domestic capacities is beneficial. In general, we show that a common methodology for de-rating 
interconnection must take into account resulting energy flows during scarcity situation. Moreover, long-term changes in generation mixes due to CMs must be considered. The major challenge, for both implicit and explicit cross-border participation, is a proper determination of the capacity demand and de-ratings. Policy makers and regulators need to find a balance between an under- or overestimating the value of non-domestic capacity with the above described consequences.

For this paper, the case study is limited to a number of generators. A more flexible demand or strategic acting of market participants could provide additional understanding on how different market designs behave.

To highlight the role of other market participants, the model could be extended in several ways. For instance, the decisionmaking for interconnection investment could be studied based on energy- and capacity-based remuneration similar to the approach proposed in [29]. This would show the long-term dement of interconnection capacities under different market settings. In combination with a more detailed representation of the grid, even more realistic long-term studies could be executed. Addressing the discussion of delivery under uncertainty would further emphasize the impact of CMs on the system opextension of the model to a stochastic equilibrium model with higher temporal resolution could elaborate on potential mismatch between contracted capacity and availability in operation.

Studying the role of authorities and system operators to se775 lect market mechanisms and set capacity demands is very important. A game-theoretical model that incorporates a hierarchical decision-making could explore a system operator anticipating the reactions of market participants during setting capacity demands and de-rating factors. This might even reveal that under certain conditions a mix of CMs is beneficial. A model extension could elaborate on the impact of being conservative or risk-averse in selecting de-ratings. This could be an extension to study the impact of risk-averse generators in capacity markets as described in [36].

\section{Acknowledgment}

Hanspeter Höschle holds a PhD fellowship of the Research Foundation - Flanders (FWO) and the Flemish Institute for Technological Research (VITO). We would like to thank the reviewers for their contributions to the methodology and recommendations to improve the case study.

\section{References}

[1] European Commission, Proposal for a DIRECTIVE OF THE EUROPEAN PARLIAMENT AND OF THE COUNCIL on common rules for the internal market in electricity 0380 (2016).

$$
\text { URL https://ec.europa.eu/energy/sites/ener/files/ }
$$

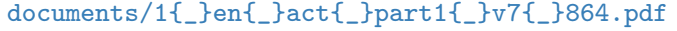

[2] R. Meyer, O. Gore, Cross-border effects of capacity mechanisms: Do uncoordinated market design changes contradict the goals of the European market integration?, Energy Econ. 51 (2015) 9-20. doi:10.1016/j.eneco.2015.06.011.

URL http://linkinghub.elsevier.com/retrieve/pii/ S0140988315001863
[3] G. Doorman, J. Barquin, L. Barroso, C. Batlle, A. Cruickshank, C. Dervieux, K. De Vos, L. de Vries, R. Flanagan, J. Gilmore, J. Greenhalg, H. Höschle, P. Mastropietro, A. Keech, M. Krupa, J. Riesz, B. LaRose, S. Schwenen, G. Thorpe, J. Wright, Capacity mechanisms: needs, solutions and state of affairs, Cigre technical brochure, Paris, France (2016).

[4] H. Höschle, G. Doorman, Capacity Mechanisms : Results from a World Wide Survey, CIGRE Sci. Eng. 7 (2017) 117-124.

URL https://lirias.kuleuven. be/handle/123456789/584883

[5] P. Mastropietro, P. Rodilla, C. Batlle, National capacity mechanisms in the European internal energy market: Opening the doors to neighbours, Energy Policy 82 (1) (2015) 38-47. doi:10.1016/j.enpol.2015.03.004.

URL http://dx.doi.org/10.1016/j.enpol.2015.03. 004http://linkinghub.elsevier.com/retrieve/pii/ S030142151500110X

[6] European Commission, Final Report of the Sector Inquiry on Capacity Mechanisms, Tech. rep. (2016).

URL http://ec.europa.eu/competition/sectors/

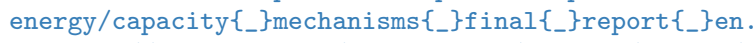
pdfhttp://ec.europa.eu/competition/sectors/energy/ capacity\{_\}mechanism\{_\}swd\{_\}en.pdf

[7] Frontier Economics, Interconnector participation in Capacity Remuneration Mechanisms, Tech. rep., Energy Norway (jan 2014).

URL http://ww. frontier-economics.com/documents/2014/ 05/frontier-report-interconnector-participation-incapacity-remuneration-mechanisms.pdf

[8] European Commission, Generation Adequacy in the internal electricity market - guidance on public interventions (2013) (2014) 1-8.

URL http://ec.europa.eu/energy/sites/ener/files/ documents/com\{_\}2013\{_\}public\{_\}intervention\{_\}swd01\{_\}en. pdf

[9] H. Höschle, K. De Vos, Implementation of a Strategic Reserve in Belgium: Product Design and Market Results, in: CIGRE Sess. 2016, 2016. URL https: //lirias .kuleuven . be/handle/123456789/548717

[10] D. Newbery, M. Grubb, Security of Supply, the Role of Interconnectors and Option Values : insights from the GB Capacity Auction, Econ. Energy Environ. Policy 4 (2) (2015) 18. doi: $10.5547 / 2160-5890.4 .2$.dnew.

URL http://www.iaee.org/en/publications/eeeparticle. aspx?id=93

[11] N. Damsgard, Capacity Markets in Europe: Impacts on Trade and Investments - A Sweco Multiclient Study, Final report (2014).

URL http://www.elforsk.se/Documents/MarketDesign/ conference/2014Papers/3\{_\}4\{_\}report.pdf

[12] Frontier Economics, Participation of interconnected capacity in the GB capacity market, Tech. rep. (2014).

URL https://www.gov.uk/government/uploads/ system/uploads/attachment\{_\}data/file/358141/

Frontier\{_\}economics __ $\left._{-}\right\}$Report $\left\{\right.$_\}Participation $\left\{_{-}\right\} \circ f\{$ _ $\}$ Interconne pdf

[13] B. Tennbakk, C. Noreng, Participation of interconnected capacity in capacity mechanisms, Tech. rep. (2014).

URL http://www.elforsk.se/Documents/MarketDesign/ projects/ER\{_\}14\{_\}28.pdf

[14] X. Lambin, T.-O. Léautier, Cross-border effects of capacity remuneration schemes in interconnected markets: who is free-riding?

URL http://www.faee.fr/files/file/aee/seminaires/2015/ Lambin-Xavier-FAEE.pdf

[15] P. C. Bhagwat, J. C. Richstein, E. J. Chappin, K. K. Iychettira, L. J. De Vries, Cross-border effects of capacity mechanisms in interconnected power systems, Util. Policy 46 (2017) 33-47. doi:10.1016/j.jup.2017.03.005.

URL http://linkinghub.elsevier.com/retrieve/pii/ S0957178716300832

[16] B. Tennbakk, P. Capros, H. Höschle, Å. Jenssen, J. Wolst, M. Zampera, Framework for cross-border participation in capacity mechanisms, Final report, European Commission (dec 2016).

URL https://ec.europa.eu/energy/sites/ener/ files/documents/cross-border $\left\{_{-}\right\} \operatorname{crm}\left\{{ }_{-}\right\}$study\{_\}-

\{_\}final\{_\}report\{_\}-\{_\}170106.pdf 
[17] R. Meyer, O. Gore, G. Brunekreeft, S. Viljainen, Analysis of Capacity Remunerative Mechanisms in Europe from the Internal Electricity Market Point of View, Elforsk rapport (mar 2014).

URL http://www.elforsk.se/Documents/MarketDesign/ projects/ER \{_\}14\{_\}22.pdf

[18] H. Höschle, C. De Jonghe, H. Le Cadre, R. Belmans, Electricity markets for energy, flexibility and availability - Impact of capacity mechanisms on the remuneration of generation technologies, Energy Econ. 66 (2017) 372-383. doi:10.1016/j.eneco.2017.06.024.

URL http://dx.doi.org/10.1016/j.eneco.2017.06. 024http://linkinghub.elsevier.com/retrieve/pii/ S0140988317302189

[19] H. Höschle, C. De Jonghe, D. Six, R. Belmans, Influence of nonharmonized capacity mechanisms in an interconnected power system on generation adequacy, in: 2016 Power Syst. Comput. Conf., IEEE, 2016, pp. 1-11. doi:10.1109/PSCC. 2016.7540839.

URL http://ieeexplore.ieee.org/document/7540839/

[20] C. De Jonghe, B. F. Hobbs, R. Belmans, Optimal Generation Mix With Short-Term Demand Response and Wind Penetration, IEEE Trans. Power Syst. 27 (2) (2012) 830-839. doi:10.1109/TPWRS . 2011 . 2174257. URL http://ieeexplore.iee. org/document/6126009/

[21] R. B. Myerson, Game theory: analysis of conflict, 6th Edition, Harvard Univ. Press, Cambridge, Mass., 1991.

[22] M. J. Osborne, A. Rubinstein, A course in game theory, MIT Press, Cambridge, Mass, 1994.

[23] S. A. Gabriel, A. J. Conejo, J. D. Fuller, B. F. Hobbs, C. Ruiz, Complementarity Modeling in Energy Markets, Vol. 180 of International Series in Operations Research \& Management Science, Springer New York, New York, NY, 2013. doi:10.1007/978-1-4419-6123-5. URL http://link. springer.com/10.1007/978-1-4419-6123-5

[24] S. Dempe, V. Kalashnikov, G. A. Pérez-Valdés, N. Kalashnykova, Bilevel Programming Problems, Energy Systems, Springer Berlin Heidelberg, Berlin, Heidelberg, 2015. doi : 10.1007/978-3-662-45827-3. URL http://link. springer. com/10.1007/978-3-662-45827-3

[25] P. Buijs, R. Belmans, Transmission investments in a multilateral context, IEEE Trans. Power Syst. 27 (1) (2012) 475-483. doi:10.1109/TPWRS . 2011.2162593.

[26] M. Jenabi, S. M. T. Fatemi Ghomi, Y. Smeers, Bi-level game approaches for coordination of generation and transmission expansion planning within a market environment, IEEE Trans. Power Syst. 28 (3) (2013) 2639-2650. doi:10.1109/TPWRS.2012.2236110.

[27] Y. Tohidi, M. R. Hesamzadeh, Multi-regional transmission planning as a non-cooperative decision-making, IEEE Trans. Power Syst. 29 (6) (2014) 2662-2671. doi:10.1109/TPWRS.2014.2312021.

[28] D. Huppmann, J. Egerer, National-strategic investment in European power transmission capacity, Eur. J. Oper. Res. 247 (1) (2015) 191-203. doi:10.1016/j.ejor.2015.05.056. URL http://dx.doi.org/10.1016/j.ejor.2015.05.056

[29] M. Saguan, L. Meeus, Impact of the regulatory framework for transmission investments on the cost of renewable energy in the EU, Energy Econ. 43 (2014) 185-194. doi:10.1016/j .eneco.2014.02.016. URL http://linkinghub.elsevier.com/retrieve/pii/ S0140988314000462

[30] European Network of Transmission System Operators for Electricity (ENTSO-E), ENTSO-E Transparency Platform (2017).

URL https://transparency.entsoe.eu/

930 [31] I. Gonzalez Aparicio, A. Zucker, F. Careri, F. Monforti, T. Huld, J. Badger, EMHIRES dataset Part I : Wind power generation, Tech. rep. (2016). doi: $10.2790 / 831549$.

URL https://setis.ec.europa.eu/sites/default/files/ reports/emhires $\left\{_{-}\right\}$dataset $\left\{_{-}\right\}$part $\left\{_{-}\right\}$i $\left\{_{-}\right\}$wind $\left\{_{-}\right\}$power $\left\{_{-}\right\}$generation $\left\{_{-}\right\} 0$. pdf

[32] I. Gonzalez Aparicio, T. Huld, F. Careri, F. Monforti, A. Zucker, EMHIRES dataset Part II : Solar power generation, Tech. rep. (2017). doi: $10.2760 / 044693$.

URL https://setis.ec.europa.eu/sites/default/ files/reports/emhires\{_\}dataset\{_\}part\{_\}ii\{_\}-

$\left\{_{-}\right\}$solar $\left\{_{-}\right\}$power $\left\{_{-}\right\}$generation.pdf

[33] K. Poncelet, H. Höschle, E. Delarue, A. Virag, W. Drhaeseleer, Selecting Representative Days for Capturing the Implications of Integrating Intermittent Renewables in Generation Expansion Planning Problems, IEEE
Trans. Power Syst. 32 (3) (2016) 1936-1948. doi:10.1109/TPWRS. 2016.2596803.

URL http://ieeexplore.ieee.org/document/7527691/

[34] A. Schröder, F. Kunz, J. Meiss, R. Mendelevitch, C. Von Hirschhausen, Current and Prospective Costs of Electricity Generation until 2050, Data documentation, Deutsches Institut für Wirtschaftsforschung (jul 2013). URL http://hdl . handle. net/10419/80348

[35] S. Simoes, W. Nijs, P. Ruiz, A. Sgobbi, D. Radu, P. Bolat, C. Thiel, S. Peteves, Assessing the long-term role of the SET Plan Energy technologies, Jrc scientific and policy report (2013). doi:10.2790/97596.

URL https://publications.europa.eu/en/publicationdetail/-/publication/07eb3787-dbe4-4b77-8df9b818a8f83b7e/language-en

[36] H. Höschle, H. Le Cadre, Y. Smeers, A. Papavasiliou, R. Belmans, An ADMM-based Method for Computing Risk-Averse Equilibrium in Capacity Markets, Under Revis. IEEE Trans. Power Syst. 